\title{
ECONOMIC INCENTIVES SURROUNDING FERTILITY: EVIDENCE FROM ALASKA'S PERMANENT FUND DIVIDEND
}

\author{
Nishant Yonzan \\ Laxman Timilsina \\ Inas Rashad Kelly \\ Working Paper 26712 \\ http://www.nber.org/papers/w26712 \\ NATIONAL BUREAU OF ECONOMIC RESEARCH \\ 1050 Massachusetts Avenue \\ Cambridge, MA 02138 \\ January 2020
}

Order of authors is reverse alphabetical. The authors thank Dhaval Dave, Fulya Ersoy, and seminar participants at the CUNY Graduate Center and Loyola Marymount University for helpful comments on earlier drafts of the paper. The views expressed herein are those of the authors and do not necessarily reflect the views of the National Bureau of Economic Research.

NBER working papers are circulated for discussion and comment purposes. They have not been peer-reviewed or been subject to the review by the NBER Board of Directors that accompanies official NBER publications.

(C) 2020 by Nishant Yonzan, Laxman Timilsina, and Inas Rashad Kelly. All rights reserved. Short sections of text, not to exceed two paragraphs, may be quoted without explicit permission provided that full credit, including $\odot$ notice, is given to the source. 
Economic Incentives Surrounding Fertility: Evidence from Alaska's Permanent Fund Dividend Nishant Yonzan, Laxman Timilsina, and Inas Rashad Kelly

NBER Working Paper No. 26712

January 2020

JEL No. H7,I1

\begin{abstract}
$\underline{\text { ABSTRACT }}$
Starting in 1982, the Alaska Permanent Fund Dividend allows each full-time resident in Alaska, including infants born in the qualifying year, to receive a sizable dividend. This dividend, which represents a form of a Universal Basic Income on a small scale, could alter incentives surrounding fertility. Using synthetic control and difference-in-differences models to account for confounding factors and unobserved heterogeneity, we model the effect of income on fertility by exploiting this income shock around 1982 using Natality files from Vital Statistics and abortion data from the Centers for Disease Control, merged with data from the Census on various state characteristics. Primary results suggest that the dividend increased fertility and reduced the spacing between births, particularly for females in the 20-44 year age group. Our results suggest that policies aimed at increasing income should consider fertility consequences and their implications for economic growth.

Nishant Yonzan

The Graduate Center, CUNY

365 Fifth Avenue

New York, NY 10016

nyonzan@gradcenter.cuny.edu

Laxman Timilsina

The Graduate Center, CUNY

365 Fifth Avenue

New York, NY 10016

ltimilsina@gradcenter.cuny.edu

Inas Rashad Kelly

Loyola Marymount University

Economics Department

University Hall 4200

1 LMU Drive

Los Angeles, CA 90045

and NBER

inas.kelly@1mu.edu
\end{abstract}




\section{Alaska Constitution Article IX, Section 15}

Section 15. Alaska Permanent Fund.

At least twenty-five percent of all mineral lease rentals, royalties, royalty sale proceeds, federal mineral revenue sharing payments and bonuses received by the State shall be placed in a permanent fund, the principal of which shall be used only for those income-producing investments specifically designated by law as eligible for permanent fund investments. All income from the permanent fund shall be deposited in the general fund unless otherwise provided by law.

\section{Introduction}

Fertility decisions can be complicated, but from an economic perspective, being financially ready is key when analyzing the demand for children. ${ }^{1}$ We exploit the introduction of an unconditional cash transfer in Alaska in 1982, the Alaska Permanent Fund Dividend (or APFD), in answering the question of whether cash transfers affect fertility. Since all residents in Alaska are eligible for the funds, we correct for endogeneity concerns through the use of synthetic control methods to generate appropriate comparison groups. We employ natality data from Vital Statistics combined with comprehensive data from the Census and Current Population Survey going as far back as 1976 in order to gauge the effects of this unconditional cash transfer on fertility. We find a 13.1 percent increase in the fertility rate for women between 15 and 44 years of age in Alaska due to the APFD. Our estimates support the theory that positive income shocks increase fertility, one of these channels being through reducing birth spacing.

In addition to providing some of the first estimates on the effects of the APFD on fertility, our study is also broadly situated within the literature that has assessed the effects of cash transfers on fertility decisions, such as those that have analyzed the effects of welfare and the earned income tax credit (EITC) on fertility decisions (Baughman and Dickert-Conlin, 2009). Compared to such welfare transfers in the U.S., the APFD has the advantage of not being tied to an individual's labor market status. Moreover, the APFD is independent of the composition of the members in the individual's household. APFD is a universal transfer to all residents in Alaska. Indeed, the amount

\footnotetext{
${ }^{1}$ A USDA (2015) report estimates that a married, middle-income couple will spend approximately $\$ 233,610$ from birth through age 17 (or \$13,742 annually) raising a child born in 2015.
} 
of APFD linearly increases in a household with an increase in the number of members within the household. This latter point is extremely important for our case. Insofar as we are concerned, the dividend transfer to a household is linear function of the size of the household-that is, the larger the household, the larger the amount of the dividend the household receives. The only condition on the dividend is one's residency status in Alaska. While any migrant would first need to establish residency before being eligible for the funds, a newborn of a resident is by default a resident of the state, and hence eligible for appropriation of the funds. Given this, our study focuses on the incentives on fertility decisions due to the APFD transfer.

First, this paper fits the existing literature on the economic incentives of fertility. Recent literature in economics has been driven by Becker's (1981) theoretical work, which suggests that the price of children and real income help to explain familial decisions surrounding fertility. This paper provides further empirical evidence.

Second, this paper provides one of the first estimates of fertility changes due to a universal cash transfer program. APFD is closely related to the Universal Basic Income (UBI). According to Hoynes and Rothstein (2019), a UBI is defined as transfers which: (a) provides a sufficiently generous cash benefit to live on, without other earnings; (b) does not phase out or phases out slowly as earnings rise; and (c) is available to a large proportion of the population, rather than being targeted to a particular subset (e.g., to single mothers). While the size of the fund is an important quantifier for Hoynes and Rothstein, Ghatak and Maniquet (2019) qualify UBI as: (a) cash transfer as opposed to in-kind transfer; (b) universal coverage; and (c) implicitly assumes a change in the tax system for it to be a budget-balanced or revenue-neutral proposal.

Broadly, there seems consensus on two key characteristics of the UBI: (1) unconditional cash disbursement, and (2) universal coverage. ${ }^{2}$ In this sense, APFD is a UBI. ${ }^{3}$ However, if one considers the size of the transfer then the APFD is not large enough for an individual's subsistence. If indeed the goal of a UBI is to provide sufficient funds for physical subsistence (see Lowrey, 2018), then the

\footnotetext{
${ }^{2}$ There are some suggestions that a UBI should be eligible only to adults. We think such targeting of UBI, combined with reduction or elimination of other transfers, would make the transfer policy regressive for families with children.

${ }^{3}$ Other studies, such as Berman (2018) and Van Parijs and Vanderborght (2017) would also classify the Alaska Permanent Fund Dividend as a UBI.
} 
APFD would not qualify as such a program. This distinction is crucial because funding becomes a seminal concern once subsistence funding is involved; the idea behind a full UBI is also to get rid of other social programs. ${ }^{4}$ This point is also at the heart of criticisms of the UBI such as that put forth by Acemoglu (2019). Nevertheless, it is useful to consider the Alaska dividend as a small-scale UBI (or simply a UI) due to its simplicity and since behavioral responses may be similar. As with a UBI, the problems of which population to target, which can cause administrative costs, inefficiencies, corruption, and inclusion and exclusion errors, are bypassed (Ghatak and Maniquet, 2019).

It is also important to note that since the APFD is a dividend disbursement from earnings from oil production in Alaska, it is not directly linked to the state's tax and transfer system. Additionally, the APFD does not replace any of the existing federal transfer programs such as the EITC. The APFD, then, can be defined as an annual unconditional lump-sum transfer to all residents in Alaska. ${ }^{5}$

One concern for any significant cash transfers is that it provides disincentives for labor market employment. However, recent evidence, both from the developing world (see Bastagli et al., 2019, Banerjee et al., 2017, Evans and Popova, 2017) and from the developed world (see Jones and Marinescu, 2018), suggests otherwise. Jones and Marinescu (2018) find no significant changes in full-time employment in Alaska, relative to its control, due to the introduction of the APFD. If, however, the goal of a UBI is to replace labor with leisure, especially in industrialized nations with a high degree of automated production, then the size of the transfer would need to be significantly larger than what the APFD is currently supplying. The relatively small size of the APFD transfer may therefore be the reason why there are no labor market effects.

Nevertheless, the size of the APFD transfer might be sufficiently significant to induce other behavioral response-namely fertility. If we do find fertility response to the APFD, then any significantly larger disbursement would certainly amplify these effects. Van Parijs and Vanderborght (2017)

\footnotetext{
${ }^{4}$ This idea came originated through increased automation and globalization, and thus the threat of unemployment (labor-displacing technological change), and also as an effective tool for poverty alleviation due to income inequality and wage stagnation.

${ }^{5}$ Kearney and Mogstad (2019) suggest that "a UBI is a guaranteed cash benefit that the government provides to all citizens." Although the APFD has been continuously disbursing funds since 1982, the disbursements are tied to profits and, in this sense, not guaranteed. For our case, we will assume that the citizens of Alaska regard the APFD as a long-term perpetual disbursement.
} 
propose an annual UBI that is equal to one-quarter of country's GDP, or $\$ 16,000$ in U.S. in 2018. In comparison, the APFD transfer in 2018 was $\$ 1,600$. In this sense, the effect we find on fertility due to the APFD is a lower bound for any UBI transfers.

If fertility rates are positively affected by the cash transfers, then policy implications are both important and varied. From an industrialized nation's perspective, it could boost the low birth rates in these countries. ${ }^{6}$ Indeed, policy makers have targeted fertility by implementing policies such as the child tax credits. One of the more generous programs was the Quebec Allowance for Newborn Children which lasted from 1988 to 1997. This program paid $\$ 500$ for the first child, $\$ 1000$ for the second child, and up to $\$ 8000$ for the third child. Using the Canadian Census data, Milligan (2005) finds that a one-time $\$ 500$ transfer increases the likelihood of having a child by $9.8 \% .^{7}$

Concerns for a developing nation go at least as far back as Reverend Malthus. He argued that The Poor Laws, a form of targeted basic income, would increase fertility rates and hence overpopulation. In recent decades, cash transfers have been used as a tool to fight poverty. Arguing the benefits of cash transfers, Banerjee et al. (2019) write: “One of the central goals of development economics has been to understand how to raise the incomes of people who are poor ... universal basic income does that by definition." However, if high fertility rates are putting a strain on the resources of the developing countries, then adopting a basic income guarantee program, all else equal, would only intensify these effects. ${ }^{8}$

The rest of the paper is organized as follows. The next section provides background on the APFD. Section 3 provides a Theoretical Framework. Section 4 is devoted to Data and Methodology. Section 5 presents our findings. Section 6 provides a summary of our findings and concludes.

\footnotetext{
${ }^{6}$ For a list of some of the ongoing targeted UBI pilot programs in the high-income economies, see Kearney and Mogstad (2019)

${ }^{7}$ See Baughman and Dickert-Conlin (2009) and Keane and Moffitt (1998) for further discussion.

${ }^{8}$ The Indian Congress Party, as one of their policies, proposed a UBI type scheme in the recent national elections. Although there have been a number of cash-transfer programs in the developing countries, there has been nothing that has been universal and for the long-term (Banerjee et al., 2019).
} 


\section{Background on the Alaska Permanent Fund Dividend}

The effect of cash transfers on behavioral changes in individuals and households are well-documented but inconclusive. The majority of the literature focuses on the potential moral hazard effects that programs that offer these transfers might have on labor market decisions (see, for example, Marinescu (2018)). Others have analyzed their effects on education (for example, with Progressa), migration (Kurland, 2017), and marriage (Low et al., 2018). The effects on fertility have generally been limited to programs that are means-tested or related to earned income and employment, such as Aid to Families with Dependent Children (AFDC), Temporary Assistance for Needy Families (TANF), EITC, unemployment insurance, or income taxes (see Baughman and Dickert-Conlin (2009) and their literature review for a more comprehensive overview of this literature). Baughman and Dickert-Conlin (2009) use birth certificate data from 1990 to 1999 and find no effect of the EITC on fertility (and even slight reductions in higher order fertility among white females). To the best of our knowledge, no prior study has directly assessed how the Alaska Permanent Fund Dividend affects fertility.

\section{Alaska Permanent Fund Dividend}

The Alaska Permanent Fund Dividend is a publicly-managed endowment established using the proceeds from oil production on Alaska's North Slope (Alaska Department of Revenue, 2017; Goldsmith (2012)). After the discovery of the petroleum and the subsequent increase in State revenue, how to manage the fund in the future was hotly debated politically. The idea of the creation of the APFD was put on vote in 1976; however, how to manage and how exactly the fund works was up for debate. Finally, in 1982, the legislators passed a law that paid all resident on equal amount regardless of age appropriate earnings from the fund (Goldsmith, 2008).

The first dividend payment, in the amount of $\$ 1000$ in nominal terms ( $\$ 2602$ in 2018 dollars) was made in 1982. The amount of the cash transfer varies from year-to-year based on a five-year average of the investment earnings of the APFD (Alaska Department of Revenue, 2017). Table 1 shows the evolution of dividends paid each year. 


\section{[Table 1 about here]}

In recent years, there has been debate regarding whether the amounts should be lowered in order to cut the state deficit, and indeed, the 2018 amount was originally supposed to be $\$ 2700$ before it was lowered to \$1600 (Herz, 2018; Rosen, 2018).

One unique feature of the APFD is that it is an income transfer available to all residents of Alaska that is not linked to income, employment, or age. The main eligibility requirements are that the individual intends to reside in Alaska indefinitely and that the individual is not incarcerated or has not committed a felony. Individuals must have resided in Alaska for the whole year of the qualifying year, which is the year prior to applying for the dividend. An exception is for children born any time during the qualifying year; they are eligible for payment provided they have an eligible sponsor. This may therefore create an incentive for potential mothers to give birth. ${ }^{9}$ The amount of the dividend is announced every year, and so individuals are unlikely to change behavior based on changes in the dollar amount. According to the U.S. Census Bureau (2017), in recent years, the payment has provided more than 10 percent of the income for the average family in the lowest income quintile in Alaska. A study also found that the dividend directly accounts for more than 20 percent of household income for the majority of Alaska Native families in remote rural areas (Knapp et al. 1984). This suggests that the amount of the dividend is sizable.

\section{Timing of the Alaska Permanent Dividend Fund}

As seen in Table 1, the amount of the dividend varies each year. Individuals apply in the first three months of the year, and the dividend is paid out in early to mid-October. According to Berman (2018), the amount of the year's dividend is known as much as six months in advance. This implies that eligible individuals may know as early as April but also suggests that individuals do not know the amount when they apply, nor can they make fertility decisions in time based on the amount. Adults are therefore unlikely to decide to have a child due to the actual monetary amount in a given year, so it would be difficult to exploit this variation to determine fertility. On average 95\% of the individuals who apply for the fund are accepted. This represents above $85 \%$ of the total

\footnotetext{
${ }^{9}$ Another mechanism could be increased adoption rate. Adoption is not explored in the current research.
} 
state population. ${ }^{10}$

Effects of the Alaska Permanent Fund Dividend

Empirical evidence on the effects of the APFD is limited. Goldsmith (2010) reviews the literature and finds no prior studies of the relationship between the dividend and aspects of economic or social behavior such as health, education status, or general welfare (p13). He says this deficit results from the difficulty in identifying the effect of the dividend on these measures independent of all the other programs and influences (p13). Furthermore, as Goldsmith (2012) notes, since most Alaskans view the dividend as a distribution of their wealth, they see no reason to study it as a phenomenon, and actually look on any attempt to study the dividend as a potential threat to its existence (p49).

A couple of studies have analyzed the inter-temporal consumption response to the Alaska Permanent Fund (Hsieh, 2003; Kueng, 2015). Jones and Marinescu (2018) find that the APFD has little or no effect on labor market decisions. This suggests that in a simple labor-leisure model, leisure hours are held constant and individuals move up to a higher utility curve and increase their total income by the amount of the dividend. This amount is higher if the number of individuals in the household is higher, and in fact increases proportionately with the number of children in the household. The role of fertility may therefore partially explain the limited labor market response.

The focus on fertility is salient for several reasons. If adults face a quantity-quality tradeoff when considering having children or additional children, an income transfer can potentially increase both quantity and quality, allowing parents to better invest in more children. On the macro level, fertility is related to population growth and, in turn, economic growth. If programs such as the one being analyzed encourage quantity of children and discourage investing in quality, then the overall impact on economic growth may be adverse. On the other hand, if they increase both quantity and quality, the overall impact is expected to be beneficial. The net overall impact on social welfare is therefore ambiguous.

\footnotetext{
${ }^{10}$ For further detail, see https://pfd.alaska.gov/Division-Info/Summary-of-Applications-and-Payments.
} 


\section{Theoretical Framework}

In Becker and Barro (1988)'s economic theory of fertility, parents are assumed to be altruistic toward their children, implying that their utility depends not only on their own consumption but also on the utility of each child and the number of children. A dynastic utility function is formulated that depends on the consumption and number of descendants in all generations. Fertility is a function of expenditures on children. In line with Becker and Barro (1988), assuming the utility of an adult ${ }^{11}$ in generation 0 is an additively separable function of own consumption $\left(c_{0}\right)$ and the utility of each child $\left(U_{1, i}\right)$, then the individual's utility function can be expressed as:

$$
U_{0}=v\left(c_{0}, n_{0}\right)+\sum_{i=1}^{n_{0}} \phi_{i}\left(U_{1, i}, n_{0}\right),
$$

where $v$ is increasing in $c$ and concave and $n_{0}$ represents the number of children. Assuming siblings are identical and $U_{0}$ depends linearly on $U_{1}$, we can simplify the parent's utility function to:

$$
U_{0}=v\left(c_{0}, n_{0}\right)+a\left(n_{0}\right) n_{0} U_{1},
$$

where $a\left(n_{0}\right)$ measures the degree of altruism toward each child. The dynastic utility function can be obtained by summing up over all generations $i$. The budget constraint faced by adults can be expressed as:

$$
w_{i}+\left(1+r_{i}\right) k_{i}=c_{i}+n_{i}\left(\beta_{i}+k_{i}+1\right)
$$

where $w$ is the wage rate, $r$ is the interest rate, $k$ is capital (with $k_{i}+1$ representing the parent's bequest of nondepreciable capital to their children) and $\beta$ is the cost of raising a child. The left-hand side is income (earned + unearned), while the right-hand side represents expenditures. Note that

\footnotetext{
${ }^{11}$ In line with Becker and Barro (1988), we ignore the effects of marriage, although the model can be extended to include this.
} 
this budget constraint does not include the labor-leisure choice, but it can be extended to do so (Tamura, 1985). The first-order conditions imply that the marginal benefit of an additional child must balance the marginal cost. ${ }^{12}$

The increase in wealth obtained by an increase in $k$, as is the case through the APFD, would imply an unambiguous increase in both $c_{0}$ and $n_{0}$ in this model. ${ }^{13}$ In this particular unique case, the increase in the number of children, $n_{0}$, would be even greater since $k$ is a positive function of $n_{0}$, as the dividend amount increases with each additional child. We therefore expect an increase in fertility due to the dividend.

Incorporating the labor-leisure choice would not change this general result, although it might reduce $k$ 's effects on $c$ and $n$ through an increase in leisure. We feel this is unlikely, however, since employment is unlikely to decrease with this transfer. That employment levels are unlikely to be greatly affected by these universal transfers is evidenced by Jones and Marinescu (2018) in this particular context and other studies analyzing the effects of UBIs in general on employment (Hoynes and Rothstein, 2019); this evidence is stronger from a theoretical perspective for low- and middle-income countries (Ghatak and Maniquet, 2019).

The income transfer is expected to have both substitution and income effects in a model looking at children versus all other goods. Since children are now (relatively) less expensive, the substitution effect implies that people will have more children (fertility will rise). While the income effect can theoretically go either way (fertility may rise or fall), there has been empirical evidence supporting Becker's (1960) theory that children are "normal" goods, suggesting that fertility rises with income, other factors held constant (Black et al., 2013; Cohen et al., 2013). ${ }^{14}$ Black et al. (2013) find that fertility increases with the husband's income using U.S. data from the mid-1970s. Cohen et al. (2013) exploit variation in Israel's child subsidy from 1999 to 2005 to find that overall fertility increases with income (although effects are small and negative at low income levels). There is an

\footnotetext{
${ }^{12}$ The findings by Becker and Barro (1988) suggest that one of the reasons for low fertility in Western economies is the declining international real interest rate and the increase in an economy's rate of technological progress. Since our study focuses on one state in a Western economy, the effects of changes in the interest rate on fertility are likely negligible (but nonzero and varying according to the monetary amount of the dividend).

${ }^{13}$ See Becker and Barro (1988) for more detail.

${ }^{14}$ Note that while, cross-sectionally, we generally observe a negative correlation between income and fertility, a more careful analysis reveals a positive relationship (Black et al., 2013).
} 
advantage to looking at unearned income, as we do here, since a female's opportunity cost of time remains unaffected. Moreover, in this context, as well as that of Cohen et al. (2013), the income transfer is a function of fertility, which affects the price of a marginal child.

\section{Data and Methodology}

\subsection{Data and Variables}

Our main outcome variable is fertility rate, which is defined as the number of live births per 1000 women between ages 15 and 44. Further, we calculate fertility rates for various sub-populations: for age groups 15-19, 20-24, 25-34, and 35-44. For each age subgroup, we calculate fertility rate using the number of live births per 1000 women in that particular age groups. To construct annual fertility rates we use live-birth data available from the public use natality files from the Vital Statistics. ${ }^{15}$ The public use Natality files have individual birth records by state across a number of years. While for some years the public files have the full population of births, in other years, for some states, they are restricted to 50 percent or 25 percent of births. As our interest is in the calculation of the number of births per 1000 women, we impute the missing births. ${ }^{16}$ For data on each state's female population, we use the Survey of Epidemiology and End Results US State and County Population Data (SEER) available via the National Bureau of Economic Research (NBER) website. ${ }^{17}$ Overall population figures for each state are also available via the NBER.

We use birth spacing as our second outcome variable. We again construct this variable using the Natality files. Birth spacing is defined as the gap, for a mother, in the number of months between the births of two children. Our sample by definition only includes those women with two or more children. We exclude twin births from this sample. There were a few observations with birth spacing of less than 9 months. Since this is not usual, we exclude them from our sample. For reasons unspecified in the public use Natality files, around 10 percent of the sample does not

\footnotetext{
${ }^{15}$ Public use Vital Statistics can be accessed here: https://www.cdc.gov/nchs/data_access/vitalstatsonline htm.

16 Annual natality data for each state and their coverage is presented in Appendix Table A.2.

${ }^{17}$ SEER data can be accessed here: https://www.nber.org/data/seer_u.s._county_population_data.html
} 
report birth spacing. In 1976 and 1977 some states did not report the birth gaps fully. ${ }^{18}$ While we expect fertility rates to increase due to APFD, we expect the opposite for birth spacing. We expect people to have more children, and for those who are planning to have additional children, to have them sooner.

Our third outcome variable pertains to abortions. These data come from the Centers for Disease Control, which have detailed information for age-specific groups. Comparisons are made with abortion data from the Guttmacher Institute for the full sample. ${ }^{19}$ Abortion data were combined with population data from the Census in order to calculate rates for the 15-44 female population. ${ }^{20}$ For Alaska in particular, data for age-specific groups is limited and is only available in 1970-1978, 1996, and 2003-2015. For this reason, we focus here on the full sample. ${ }^{21}$ We expect people to have fewer abortions as a result of the APFD.

For the control variables we use data from the Current Population Survey (CPS) available from the Integrated Public Use Microdata Series (Flood et al., 2018). ${ }^{22}$ Since Alaska can only be identified in the CPS starting 1976, our annual time series for our variables, and our study itself, starts in this year. All our variables are calculated for each state and year when appropriate for the 15-44 female age group. For each state we calculate the total population, women's share of the total population, level of education, labor market outcomes, and a variable that proxies for race-the share of white individuals in the population. We divide the level of education into three categories-those having less than high school, high school degree, or college degree-and calculate shares for each. We include a measure of labor market participation for women in each state. Women's labor force participation is measured as the share of the women aged 18 to 65 who earn positive labor income. We further calculate the share of women in the labor force for each state. We also use percentage of births occurring in Metropolitan Statistical Areas (MSAs). We calculate this variable for each state using the Natality files.

\footnotetext{
${ }^{18}$ Appendix Table A.2 explains the detailed breakdown of the sample.

${ }^{19} \mathrm{CDC}$ data for abortions are obtained from the Abortion Surveillance Report, available from 1970 onwards. Data from the Guttmacher Institute are available at: https : / /www. guttmacher .org/united-states/abortion.

${ }^{20}$ State population by age from the Census can be found at: https://www. census.gov/data/datasets/time-series / demo/popest/1970s-county.html.

${ }^{21}$ For the full sample, we have data for Alaska for 1970-1997 and 2003-2015. We therefore have information for the period of analysis (1976-1988).

${ }^{22}$ IPUMS-CPS data are available here: https : / / www . i pums . org .
} 
In addition, we include a measure of income. GDP per capita is derived from the Bureau of Economic Analysis (BEA). Specifically, we use the following file: "SA1 Personal Income Summary: Personal Income, Population, Per Capita Personal Income." From this file we use the Per Capita Personal Income as our proxy for state per capita GDP.

\subsection{Methodology}

Below we present a brief discussion of the synthetic control (SC) methodology; for a detailed explanation see Abadie et al. (2010). In what follows, we have used the term "treatment" and "intervention" to imply the start of the APFD in 1982. Hence the years prior to 1982 are referred to as pre-treatment and years after post-treatment. It follows that the "treated unit" in our study is Alaska.

The synthetic counterfactual will be composed of a convex combination of $J-1$ units in the vector $J \in\{2,3, \ldots, j\}$, each contributing weights $w_{j}$. Our treatment unit is $j=1$. The weight vector, $W$, then is a $(J-1) \times 1$ vector of unit weights use to construct the counterfactual. In line with Abadie et al. (2010), we impose two restrictions on the weights ${ }^{23}$ : first, we impose that the weights are nonnegative, $w_{j} \geq 0$, and second, that their sum is bounded above to equal a single unit, $\sum_{j=1}^{J} w_{j}=1$. The relaxation of the first restriction, which allows for negative weights, would in turn find controls that better match the trend of the treatment unit in the pre-intervention period (see Jones and Marinescu (2018) for further discussions).

We have a total of $t \in\{1,2, \ldots, T\}$ periods. $T_{0}$ is the period of intervention. So, there are $t \in\left\{1,2, \ldots, T_{0}\right\}$ pre-intervention periods and $t \in\left\{T_{0}+1, T_{0}+2, \ldots, T\right\}$ post-intervention periods.

We define $D_{j t}$ as the presence or absence of the treatment. So:

\footnotetext{
${ }^{23}$ Following Tanndal and Waldenström (2018) we can assume that the weights are not negative, nor do they sum to less than one due to the non-symmetric nature of fertility rates. Doudchenko and Imbens (2016) have suggested that it may feasible to use non-restrictive weights for symmetric outcome variables.
} 


$$
D_{j t}=\left\{\begin{array}{l}
1 \text { for the treatment unit, } \forall t \in\left\{T_{0}+1, \ldots, T\right\}, \\
0 \text { for the treatment unit } \forall t \in\left\{1,2, \ldots, T_{0}\right\}, \text { and } \\
0 \text { for the control units } \forall t \in\{1,2, \ldots, T\}
\end{array}\right.
$$

Following Rubin (1974), we can think of the effect on the outcome variable without treatment as follows:

$$
y_{j t}(D=0)=\delta_{t}+\beta_{t} Z_{j}+\lambda_{t} \mu_{j}+\varepsilon_{j t}
$$

where, $y_{j t}(D=0)\left(y_{j t}(0)\right.$ henceforth $)$ is the outcome without the intervention, $\delta_{t}$ are the time fixed effects, $\mu_{j}$ are unit fixed effects, and $\varepsilon_{j t}$ are unit-specific time shocks. $Z_{j}$ is a $K \times 1$ vector of variables that influence the outcome.

Then the treated outcome becomes:

$$
y_{j t}(1)=\theta_{j t}+y_{j t}(0)
$$

where, $\theta_{j t}$ is the effect of the treatment for the treated unit. The treatment is the difference between the treated state, that is $y_{j t}(1)$, and the untreated state, $y_{j t}(0)$. In our framework, the effect of the treatment can be expressed as follows:

$$
\theta_{1 t}=y_{1 t}(1)-y_{1 t}(0), \forall t \in\left\{T_{0}+1, \ldots, T\right\}
$$

Since we do not observe $y_{1 t}(0)$ in the post-intervention period for the treated unit, we estimate it through a counterfactual. The SC estimator estimates $y_{1 t}(0)$ using a combination of weights with a pool of donor units. The SC estimator can be expressed as: 


$$
\hat{\theta}_{1 t}=y_{1 t}(1)-\sum_{j=2}^{J} w_{j} \cdot y_{j t}(1), \forall t \in\left\{T_{0}+1, \ldots, T\right\} .
$$

Since we know the outcome for the treatment and control units, it remains for us to estimate the weights, $w_{j}$. These weights are chosen such that we minimize the pre-intervention gap between the treated series and the estimated counterfactual series. The optimal weights are calculated such that:

$$
w^{*}(V)=\underset{w}{\operatorname{argmin}}\left(X_{1}-\sum_{j=2}^{J} w_{j} \cdot X_{j}\right)^{\prime} V\left(X_{1}-\sum_{j=2}^{J} w_{j} \cdot X_{j}\right),
$$

where, $X$ is a $\left(K+t_{y}\right) \times 1$ vector of variables with all the regressors and the outcome variable, $\left(Z_{j}^{\prime}, y_{j 1}, y_{j 2}, \ldots, y_{j T_{0}}\right)^{\prime}$. We pick $V$ such that:

$$
V^{*}=\underset{v}{\operatorname{argmin}} \frac{1}{T_{0}} \sum_{t=1}^{T_{0}}\left(y_{1 t}-\sum_{j=2}^{J} w_{j}^{*}(V) \cdot y_{j t}\right)^{2} .
$$

The synthetic control (SC) estimator can then be expressed as:

$$
\hat{\theta}_{1 t}=y_{1 t}-\sum_{j=2}^{J} w_{j}^{*} \cdot y_{j t}, \forall t \in\left\{T_{0}+1, \ldots, T\right\} .
$$

Further, we can calculate the pre-treatment match between the treatment and control units. This is given by the root mean squared prediction error (RMSPE):

$$
R M S P E=\sqrt{\frac{1}{T_{0}} \sum_{t=1}^{T_{0}}\left(y_{1 t}-\sum_{j=2}^{J} w_{j}^{*} \cdot y_{j t}\right)^{2}} .
$$

As the SC methodology does not have a traditional way to calculate the $p$-value, for inference we follow Abadie et al. (2015). They define the $p$-value as: 


$$
p \text {-value }=\frac{\sum_{j=2}^{J} \sum_{t}^{T} 1\left\{\left|\hat{\theta}_{1, T_{0}}\right| \leq\left|\hat{\theta}_{j, t}\right|\right\}}{N_{j t}}
$$

where, $N_{j t}$ is the total number of placebo SC studies, and $\hat{\theta}_{j, t}$ is the treatment effect for these placebo studies. Essentially, we will conduct SC methodology studies with each of the fifty states as the treated unit and estimate equation 11. These studies are referred to as placebo studies. For the $p$-value, we then compare the effect size of the actual treated unit, Alaska, to these placebo effects. The $p$-value in equation 13 expresses the share of placebo effects that are larger than the effect on the actual study.

\section{Results}

We first present results from the synthetic control studies using fertility rate as the outcome variable. This is followed by the birth spacing and finally by the abortion rate variables of interest. For each outcome variable, we discuss the raw trends followed by the results from the SC studies. Additionally, we also compare and contrast the SC estimates for Alaska with those of the placebo studies. Finally, to check the sensitivity of our SC estimates, we will present results using the Difference-in-Differences specifications. The latter results are presented in the robustness checks subsection. We limit our study to the years 1976 to 1988 . This is in part due to the need to tighten the window around the policy to mitigate potential confounding effects of macro factors and in part due to data availability.

\subsection{Results for Fertility Rate}

\subsubsection{Raw trends}

Table 2 presents the average annual fertility rates for Alaska and the US excluding Alaska by each age group over time. Fertility rates for Alaska are consistently higher than those for the rest of the 
United States for all age groups. The fertility rate for the general population-that is, the 15-44 age group-has been declining steadily since the early 1980s both in Alaska and in all other states. In the period between 1976 and 1988, the fertility rate in Alaska for the 15-44 population was on average 88 births per 1000 women and the average fertility rate for the rest of the US was 68 . While this rate remained stable at around 69 annual live births in the 1976-1982 period for the rest of the country, in Alaska it rose from 80 in 1976 to 95 annual live births in 1982. This increase in fertility in Alaska was possibly driven by the migration boom corresponding to the building of the oil pipeline in the mid-1970s. Post 1982, however, there is a decline in fertility rates in Alaska. This decline in fertility rates post 1982 is driven by the decrease in fertility rates of women in the youngest age groups (15-19 and 20-24). For the age groups 25-34 and 35-44, there is an increase in fertility rates in the whole decade between 1976 and 1988 in Alaska. These fertility trends for the various age groups mimics the trends in average fertility rates for the rest of the country.

[Table 2 about here]

\subsubsection{SC results}

Table 3 reports descriptive statistics of the variables used for matching Alaska and its synthetic control. The states and the weights of each state used for synthetic control counterfactuals are presented in Table A.1. Columns (1) and (2) of Table 3 reports the pre-treatment averages of the variables for the 15-44 age group for Alaska and its synthetic counterfactual respectively. The variables are averaged for all the pre-treatment period. Note that we have used the average of the outcome variable in the SC matching process. We provide SC results using only the last year of outcome for matching in Appendix B. The balance between the series of the other age groups are presented in columns (3)-(6). It is assuring to note that the averages of these variables across the different controls are fairly close to the actual values for Alaska.

[Table 3 about here]

Table 4 reports the estimated effects from the SC studies with fertility rate as the outcome of 
interest. The SC effect is averaged over all the post treatment years-that is, for the years 1983 to 1988. ${ }^{24}$ Column (1) of this table reports the estimate for the overall population, the 15-44 age group. This estimate suggests that the average post-treatment difference in fertility rates between Alaska and its synthetic control was 11.3, or Alaska on average had 11.3 more annual live births per 1000 women compared to its control. The $p$-value reported here is calculated using equation 13. It can be inferred from the $p$-value that the size of the estimate for Alaska was in the $98^{\text {th }}$ percentile compared to SC estimates of the placebo studies. We also report the pre-treatment match, or the root mean square prediction error (RMSPE), in fertility trends between Alaska and its synthetic control. Furthermore, we also present the ranking of this RMSPE from the Alaska study relative to a distribution of the RMSPEs from all the placebo studies. The RMSPE-percentile suggests that Alaska's pre-treatment match was better than the match in only 15 percent of the placebo SC studies.

Columns (2)-(5) of Table 4 reports estimates from the SC studies for the 15-19, 20-24, 25-34, and 35-44 age groups, respectively. For the 15-19 age group, we do not find any significant difference in fertility rates between Alaska and its control. We do, however, find significantly large effects on fertility rate for all the other age groups. The 20-24 age group in Alaska has more than 20.3 births on average compared to its control in the period after the start of the APFD. Considering that the average fertility rate for this age group before the introduction of APFD was 163.1, the estimate of 20.3 suggests an increase in fertility rates of 12.4 percent. Similarly, the estimate for the 25-34 group is 14.1 , which is a 14.3 percent increase over the mean fertility of this group. The estimate for $35-44$ age group is 2.8 , which is a 16.3 percent increase in fertility rate over the age group's pre-treatment mean.

\section{[Table 4 about here]}

Figure 1 presents the pre- and post-treatment trends in the fertility rate for various age groups and its respective synthetic control series. For the 15-44 age group in panel A, we find a positive impact on fertility in Alaska in the post-treatment period relative to its control. Recall that the

\footnotetext{
${ }^{24}$ The estimates in Table 4 are calculated using $\hat{\theta}_{1, t}$ from equation 11 as follows: $\hat{\theta}_{1}=\sum_{t=T_{0}+1}^{T} \frac{1}{\left(T-\left(T_{0}+1\right)\right)} \hat{\theta}_{1, t}$.
} 
average difference for the 1983-88 period was 11.3 births (see column (1) of Table 4). Given that the pre-treatment average fertility rate for Alaska is 85.9, APFD effectively increased the fertility rate in Alaska by 13.1 percent in the $1983-88$ period. Note that this average effect on fertility rate in Alaska is not driven by an odd year. It is clear from Panel A of Figure 1 that the effect remains persistent in all periods after the implementation of APFD.

Similarly, we find visible effects of the APFD on fertility rates for all age groups over the age of 20 years. The effects are strongest for the oldest age group in our study. It is also interesting to note the null effect for the 15-19 group.

[Figure 1 about here]

Figure 2 reports the size of the annual effects from the SC study for Alaska and all placebo SC studies. The size of the effect is the annual difference in trends between Alaska and its synthetic control series presented in Figure 1. The annual effect size for Alaska is represented by the broken line in all panels. The gray solid lines represent the size of the effects for each placebo study. In an ideal scenario, we should expect to see zero annual effects before the intervention-that is, the effect graph should perfectly align with the vertical line at zero. This would be the case if the trends in Alaska exactly matched the trends in its control in Figure 1. The pre-treatment match of SC studies for Alaska is fair considering the placebo studies. Relative to the placebo studies, the effect size for fertility rate in Alaska is significantly large for all age groups besides the teen group in the post-APFD period.

Note that, relative to the placebos, the effect for Alaska is large for all age groups over the age of 20 years. While the pre-treatment match for the 25-34 age group is not exact, the match for 20-24 and 35-44 is relatively better compared to their placebo studies.

[Figure 2 about here] 


\subsection{Results for Birth Spacing}

\subsubsection{Raw trends}

While the fertility rate in the 1976-88 period is higher in Alaska compared to the rest of the US, birth spacing is lower. Table 5 presents descriptive statistics on birth spacing for Alaska and the US excluding Alaska. Birth spacing is measured as the average number of months between the birth of two children. This is again calculated for various age groups. For the 15-44 age group, the gap between births is on average 43 months in Alaska and 45 months in the rest of the country. Although small, this difference in birth spacing is primarily driven by the 25-34 and 35-44 groups. The difference in birth spacing between Alaska and the rest of the US in the 1976-1988 period is one month for the 20-24 age group and non-existent for the 15-19 age group. In the US in this time period, conditional on having a child, the 15-19 and 20-24 age groups waited on average within 2-3 years for their next child, while the 25-34 and 35-44 groups waited on average between 4-7 years.

[Table 5 about here]

\subsubsection{SC results}

Table 6 reports descriptive statistics of the variables used for matching Alaska and its synthetic control. As with fertility rates in Table 4, the actual and synthetic control pre-treatment averages for all age groups are fairly close.

[Table 6 about here]

Table 7 reports the SC estimates for birth spacing. We find that estimates for the 15-44 age group is not significantly different from zero. Or in this case, the estimate is not significantly large relative to its placebos. This is also the case for all age groups below the age of 35 years. We do, however, observe that the direction of all the estimates for birth spacing is consistent with our hypothesis. 
We do find a large negative effect on birth spacing for the 35-44 age group. This estimate suggests a 3.9 month decline in birth spacing for the 35-44 age group in Alaska compared to its control. This is about a 5.2 percent decline in the gap between births for this group. Another way of looking at this is that on average a mother with a child was likely to have another child 3.8 months sooner in Alaska relative its control. This magnitude of the effect size, although not significant in the traditional sense, is larger than 70 percent of the placebos. The pre-treatment match for this group is as good as half its placebos.

[Table 7 about here]

The trends in birth spacing are presented in Figure 3 and the comparison of the effect size with placebo effect sizes are presented in Figure 4. As with the fertility rate study, we find no effect for the 15-19 group. There is, however, some evidence of declining trends in birth spacing for all the age groups over 20 years relative to their controls.

[Figure 3 about here]

[Figure 4 about here]

\subsection{Results for Abortion Rates}

\subsubsection{Raw trends}

Abortion rate is measured as the number of reported abortions per 1000 women between the ages of 15 and 44. Table 8 reports the the raw trends in abortion rates for Alaska and the U.S average excluding Alaska. As explained in the data section, abortion rates are only reported here for the overall (15-44) population. There are fewer abortions in Alaska compared to the average of all other states in the U.S. Alaska in the 1976-1988 period had on average 13.6 abortions per 1000 women, while the US average, not including Alaska, had 21.5 abortions per 1000 women. 
[Table 8 about here]

\subsubsection{SC results}

Table 9 presents the pre-treatment balance of the variables, and Table 10 presents the SC estimates for studies with abortion rate. The estimate in Table 10 suggests a small increase in abortion rate in Alaska relative to its control. However, this effect size is smaller than two thirds of the placebo studies.

[Table 9 about here]

[Table 10 about here]

Panel A of Figure 5 shows the trends in abortion rates for Alaska and its SC counterfactual. The trends do not match well in the pre-treament period and they do not diverge from each other in the post-treatment period. We can also confirm the relative no effect in abortion rates from the placebo comparisons in Panel B of the same figure. We do not find any significant effect on abortion rates in Alaska due to the APFD.

[Figure 5 about here]

While our findings for fertility rate and birth spacing are consistent with our hypothesis, those for abortion do not appear to be. This is unsurprising. The two former outcomes relate mostly to planned pregnancy and hence are directly influenced by income shocks such as that represented by the APFD. Abortions on the other hand, are generally unplanned pregnancies and hence the effect due to income shocks is less likely to occur. 


\subsection{Robustness Checks}

In this section, we test the sensitivity of our SC estimates using the Difference-in-Differences (DiD) framework. The DiD framework differs from SC methodology in that while SC study forces a pre-treatment match between the series for the treated and the control units, DiD relaxes this assumption. DiD allows for a pre-treatment difference in levels of the trends for the treated and control units. However, the DiD framework imposes a further assumption that the trends between the treated and control units are "parallel." The DiD studies are especially important for robustness of the estimates as the pre-treament match in the SC studies were not optimum.

We use the DiD methodology to compare Alaska with two sets of controls. Our first control does not impose any restrictions on the states used as the counterfactual; that is, we perform a DiD study with all states as part of the counterfactual for Alaska. For the second control, we use only the states that had positive weights in the SC study. The states used in the latter control group are listed in Table A.1.

We present results from the DiD study for fertility rate in Table 11, birth spacing in Table 12, and abortion rate in Table 13. Panel A of each table presents the DiD study for the 15-44 age group; the other panels present results from studies with various age groups. Columns (1)-(4) report DiD estimates using various specifications for our first control group-all the states in the US. Columns (5) and (6) present the DiD results from the restricted control group.

Column (4) of Table 11 presents DiD results using all states as the control. For the 15-44 age group, we find an increase in fertility rate of 6.9 more births in Alaska per 1000 women; this represents an 10.1 percent increase in fertility rate in Alaska over the sample average. The DiD estimates for fertility are robust to controlling for time and state fixed-effects or a list of control variables used in the SC study. The effect size increases if we restrict our control to the states used in the SC study. For this age group, the DiD effect size is 11.6 , which is a 13.6 percent increase over the mean pre-treatment fertility of this age group.

As with the SC study, the DiD estimates for fertility rates are not significant for the teen group. 
The DiD estimates for fertility rate are significant for all other age groups. For the 20-24 age group, fertility rate in Alaska increased between 13.7 and 24.2 percent over its controls. For the 25-34 group, fertility rate increased between 14.4 and 15.0 percent, and for the 35-44 group, fertility rate increased between 16.1 and 18.0 percent.

[Table 11 about here]

Consistent with the SC study for birth spacing, we find negative effects from our DiD studies for birth spacing. These estimates are reported in Table 12. Only the "oldest" age group for the DiD studies shows consistently significant effects. As expected, the birth spacing for this group decreases. However, this decrease remains very small, less than a percent over the mean of the sample.

[Table 12 about here]

As with the SC studies, we do not find any significant results for the abortion rates using the DiD framework.

[Table 13 about here]

\section{Conclusion}

Previous studies on the Alaska Permanent Fund Dividend, which allowed each full-time resident in Alaska to receive a sizable dividend starting in 1982, suggest that it had limited employment effects, suggesting that the labor market consequences of having such a dividend as a UBI may be minimal. Perhaps this is an effect due to the relatively small size of the disbursement. A channel whereby this is occurring may be through increased fertility if the dividend encourages individuals

to have children. While studies have analyzed the effects of various welfare benefits on fertility, 
no previous study to our knowledge has analyzed the effect of a universal dividend such as that provided by Alaska on fertility outcomes. Using synthetic control models as the primary tool to ensure our results are internally valid, we exploit the introduction of this dividend in Alaska in 1982 to explore the effects of the dividend on the number of children (fertility), birth spacing for those with more than one child, and the number of abortions. Our analysis is done separately by age groups (15-19, 20-24, 25-34, and 35-44) in addition to the pooled sample (15-44 year olds). We find that fertility increases in Alaska by 11.3 births per 1000 females (all age groups) due to the dividend. While we find no effect due to the cash transfer on the fertility of the teen group, the effect is particularly pronounced for the age groups over 20 years of age. We find an effect of 20.3 births for 20-24 year olds, representing a 12.4 percent increase, 14.1 births for 25-34 year olds, representing a 14.3 percent increase, and 2.8 births for the 35-44 year olds, representing a 16.9 percent increase. The effects for birth spacing are generally in the expected direction but imprecisely measured. We do not find significant effects for abortion rates.

While we argue that the Alaska Permanent Fund Dividend does not meet all of the requirements to classify it as a UBI (as the amount, although sizable, is still too small), it is an unconditional and universal transfer. This suggests that, when considering policies surrounding UBIs, one consideration is the effect it may have on fertility. For those on the margin when deciding whether to have a child or additional child, the increased income may increase both the quality and quantity of children; the effect on quality, however, may not hold further away from the margin. These are factors to consider when analyzing the long-run effects of increased fertility on economic growth and the implications for skilled versus unskilled labor. ${ }^{25}$

\footnotetext{
${ }^{25}$ Please refer to the literature on fertility and economic growth, such as Day (2016) study that presents an overlapping generations model in this context, for insights into this dynamic relationship.
} 


\section{References}

Abadie, A., Diamond, A., and Hainmueller, J. (2010). Synthetic control methods for comparative case studies: Estimating the effect of californias tobacco control program. Journal of the American statistical Association, 105(490):493-505.

Abadie, A., Diamond, A., and Hainmueller, J. (2015). Comparative politics and the synthetic control method. American Journal of Political Science, 59(2):495-510.

Acemoglu, D. (2019). Why universal basic income is a bad idea. Project Syndicate, 7.

Alaska, D. o. R. (2017). http://www.tax.alaska.gov/programs/programs/reports/ AnnualReport. aspx?Year=2017. Accessed: 20 October 2018.

Alaska, D. o. R. P. F. D. D. (2019). https://pfd.alaska.gov/Division-Info/Summary-of -Applications-and-Payments. Accessed 30 October 2019.

Banerjee, A., Niehaus, P., and Suri, T. (2019). Universal basic income in the developing world. Annual Review of Economics, 11:959-983.

Banerjee, A. V., Hanna, R., Kreindler, G. E., and Olken, B. A. (2017). Debunking the stereotype of the lazy welfare recipient: Evidence from cash transfer programs. The World Bank Research Observer, 32(2):155-184.

Bastagli, F., Hagen-Zanker, J., Harman, L., Barca, V., Sturge, G., and Schmidt, T. (2019). The impact of cash transfers: A review of the evidence from low-and middle-income countries. Journal of Social Policy, 48(3):569-594.

Baughman, R. and Dickert-Conlin, S. (2009). The earned income tax credit and fertility. Journal of Population Economics, 22(3):537-563.

Becker, G. (1981). A Treatise on the Family. Cambridge, MA, Harvard UniversityPress.

Becker, G. S. and Barro, R. J. (1988). A reformulation of the economic theory of fertility. The Quarterly Journal of Economics, 103(1):1-25.

Berman, M. (2018). Resource rents, universal basic income, and poverty among alaskas indigenous peoples. World Development, 106:161-172.

Black, D., Kolesnikova, N., Sanders, S. G., and Taylor, L. J. (2013). Are children "normal"? The Review of Economics and Statistics, 95(1):21-33.

Cohen, A., Dehejia, R., and Romanov, D. (2013). Financial incentives and fertility. The Review of Economics and Statistics, 95(1):1-20.

Day, C. (2016). Fertility and economic growth: The role of workforce skill composition and child care prices. Oxford Economic Papers, 68(2):546-565.

Doudchenko, N. and Imbens, G. W. (2016). Balancing, regression, difference-in-differences and synthetic control methods: A synthesis. National Bureau of Economic Research Working Paper No. 25538, Cambridge, MA.

Evans, D. K. and Popova, A. (2017). Cash transfers and temptation goods. Economic Development and Cultural Change, 65(2):189-221. 
Flood, S., King, M., Ruggles, S., and Warren, J. R. (2018). Integrated public use microdata series, current population survey: Version 6.0. Minneapolis: University of Minnesota. DOI: https: // doi.org/10.18128/D030.V6.0.

Ghatak, M. and Maniquet, F. (2019). Universal basic income: some theoretical aspects. Annual Review of Economics, 11:895-928.

Goldsmith, O. S. (2010). The Alaska Permanent Fund Dividend: A case study in implementation of a basic income guarantee.

Goldsmith, O. S. (2012). The economic and social impacts of the permanent fund dividend on Alaska. In Alaska's permanent fund dividend, pages 49-63. Springer.

Herz, N. (2018). Alaska house votes to more than double PFDs, splintering majority and threatening budget progress. https://www.adn.com/politics/alaska-legislature/ 2018/03/26/alaska-house-votes-to-more-than-double-pfds-splintering-majority-and -threatening-budget-progress/. Accessed: 17 October 2018.

Hoynes, H. W. and Rothstein, J. (2019). Universal basic income in the US and advanced countries. National Bureau of Economic Research Working Paper No. 25538, Cambridge, MA.

Hsieh, C.-T. (2003). Do consumers react to anticipated income changes? evidence from the Alaska permanent fund. American Economic Review, 93(1):397-405.

Jones, D. and Marinescu, I. (2018). The labor market impacts of universal and permanent cash transfers: Evidence from the Alaska permanent fund. National Bureau of Economic Research Working Paper No. 24312, Cambridge, MA.

Keane, M. and Moffitt, R. (1998). A structural model of multiple welfare program participation and labor supply. International economic review, pages 553-589.

Kearney, M. S. and Mogstad, M. (2019). Universal basic income (ubi) as a policy response to current challenges. Report, Aspen Institute, pages 1-19.

Kueng, L. (2015). Revisiting the response of household spending to the Alaska Permanent Fund Dividend using CE data. Available at SSRN 2634005.

Kurland, S. (2017). Effects of transfer income on migration and rural unemployment: Evidence from the alaska permanent fund dividend, thesis, department of economics, stanford university, stanford ca. Available at: https://economics.stanford.edu/sites/default/files/ publications/kurland_sam_honorthesis-final_5-4-17.pdf. Accessed: 19 October 2018.

Low, H., Meghir, C., Pistaferri, L., and Voena, A. (2018). Marriage, labor supply and the dynamics of the social safety net. National Bureau of Economic Research Working Paper No. 24356, Cambridge, MA).

Lowrey, A. (2018). Give People Money: The simple idea to solve inequality and revolutionise our lives. Random House.

Marinescu, I. (2018). No strings attached: the behavioral effects of us unconditional cash transfer programs. National Bureau of Economic Research Working Paper No. 24337, Cambridge, MA.

Milligan, K. (2005). Subsidizing the stork: New evidence on tax incentives and fertility. Review of Economics and statistics, 87(3):539-555. 
Quistorff, B. and Galiani, S. (2017). The synth_runner package: Utilities to automate synthetic control estimation using synth. Stata Journal, (17):834-849.

Rosen, Y. (2018). For 40 years, alaska has modeled a universal income. now thats in peril. http://inthesetimes.com/article/21544/alaska-universal-basic-income -dividend-taxes-permanent-fund. Accessed 30 October 2019.

Rubin, D. B. (1974). Estimating causal effects of treatments in randomized and nonrandomized studies. Journal of Educational Psychology, 66(5):688.

Tamura, R. (1985). A note on the dynastic family. In Workshop in Applications of Economics, University of Chicago.

Tanndal, J. and Waldenström, D. (2018). Does financial deregulation boost top incomes? evidence from the big bang. Economica, 85(338):232-265.

Van Parijs, P. and Vanderborght, Y. (2017). Basic income: A radical proposal for a free society and a sane economy. Harvard University Press. 
Figure 1: Alaska and Synthetic Control Trends, Fertility Rate

Panel A: 15-44

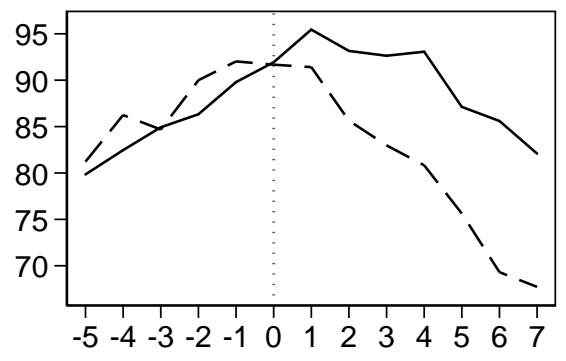

Panel C: $20-24$

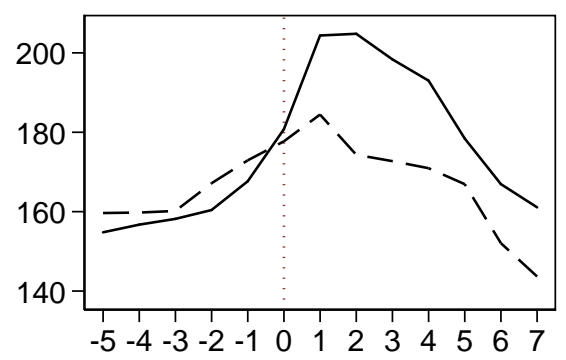

Panel E: 35-44

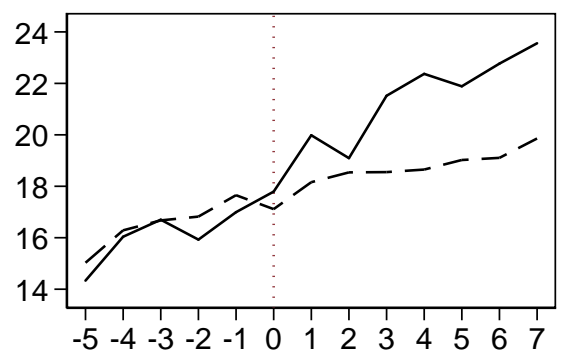

Panel B: 15-19

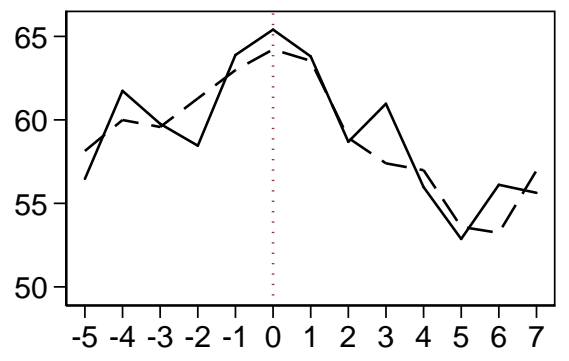

Panel D: 25-34

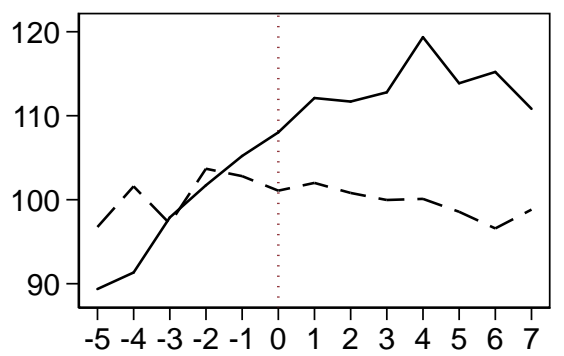

\section{$\longrightarrow$ Alaska $\quad-\quad-$ SC Control}

Notes: This figure shows the trends in fertility rate for Alaska and its respective synthetic controls by various age groups. The states and their corresponding weights used for the construction of the synthetic controls are reported in Table A.1. The $\mathrm{x}$-axis measures periods, in years, before and after the introduction of APFD. The year APFD was introduced, 1982, is marked by a vertical line at period zero. The $\mathrm{y}$-axis measures number of live births per 1000 women in the respective age group. 
Figure 2: Comparison of Alaska and Placebo SC Effects, Fertility Rate

Panel A: 15-44

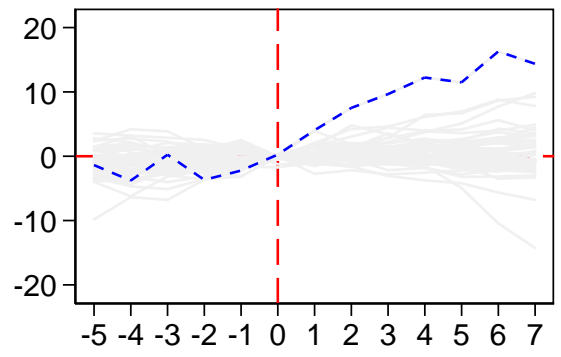

Panel C: 20-24

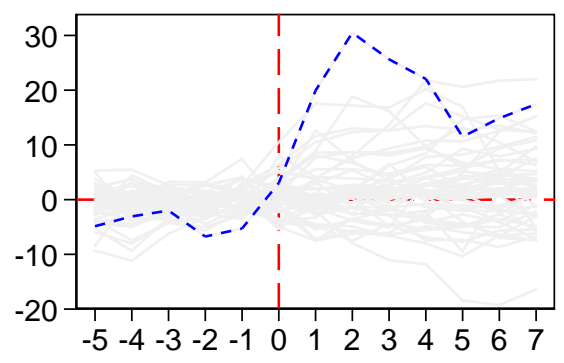

Panel E: 35-44

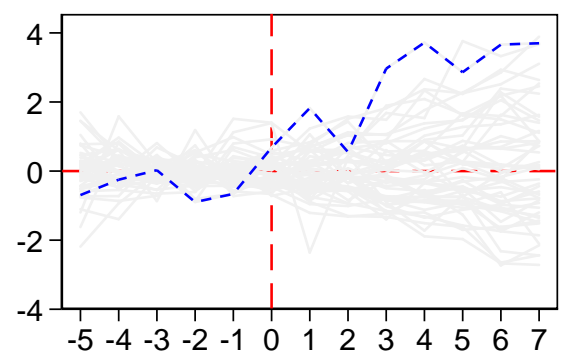

Panel B: 15-19

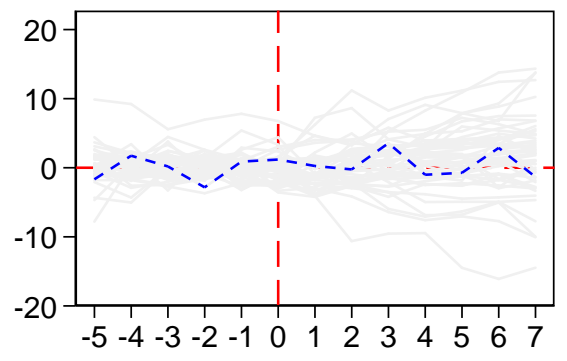

\section{Panel D: 25-34}

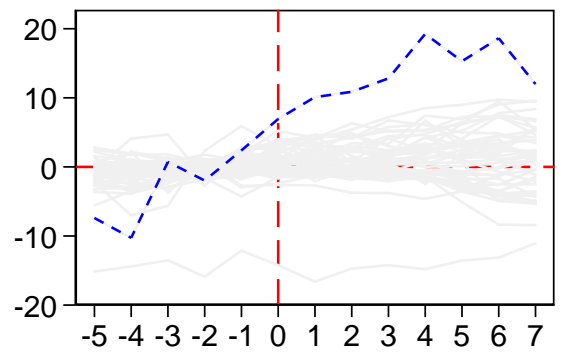

\section{- - - - Alaska Placebos}

Notes: This figure shows the difference in fertility rate between Alaska and its synthetic controls (dashed series), and the differences for all placebo states with respect to its corresponding synthetic controls (gray series). The x-axis measures periods, in years, before and after the introduction of APFD. The year APFD was introduced, 1982, is marked by a vertical line at period zero. The $y$-axis measures the number of live births per 1000 women in the respective age group. 
Figure 3: Alaska and Synthetic Control Trends, Birth Spacing

Panel A: 15-44

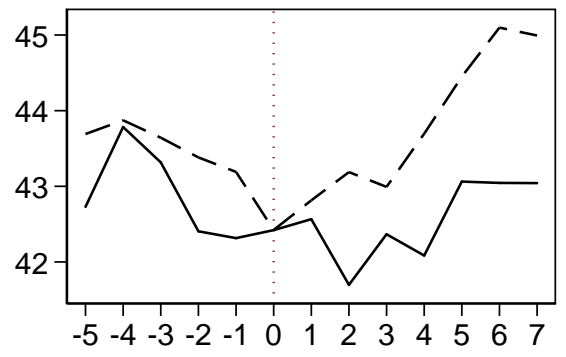

Panel C: $20-24$

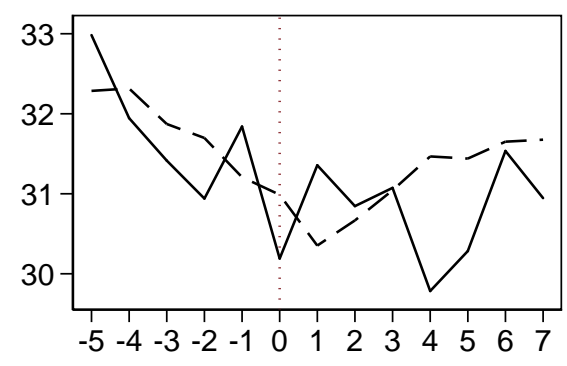

Panel E: 35-44

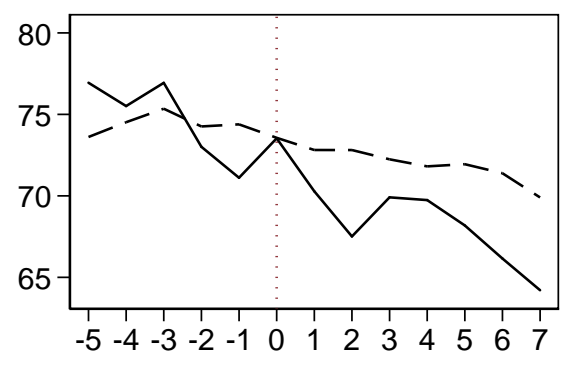

Panel B: $15-19$

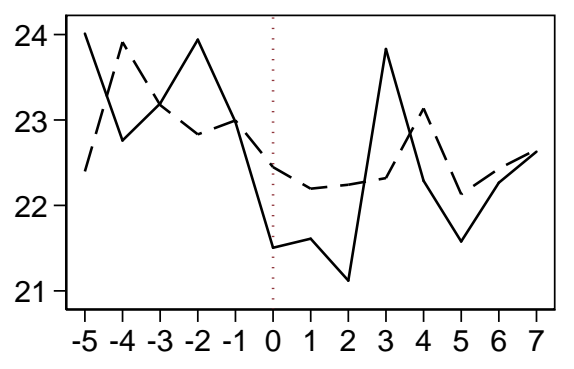

Panel D: 25-34

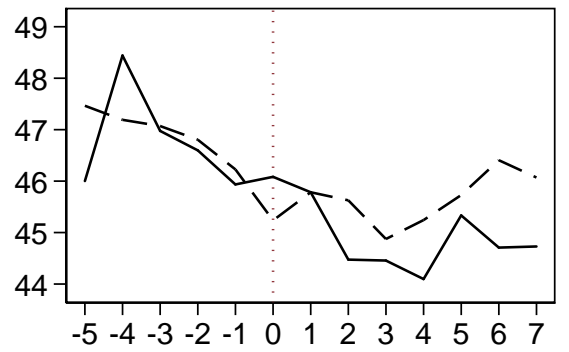

Notes: This figure shows the trends in birth spacing for Alaska and its respective synthetic controls by various age groups. The states and their corresponding weights used for the construction of the synthetic controls are reported in Table A.1. The x-axis measures periods, in years, before and after the introduction of APFD. The year APFD was introduced, 1982, is marked by a vertical line at period zero. The y-axis measures the average number of months between two live births for a woman in the respective age group. 
Figure 4: Comparison of Alaska and Placebo SC Effects, Birth Spacing

Panel A: 15-44

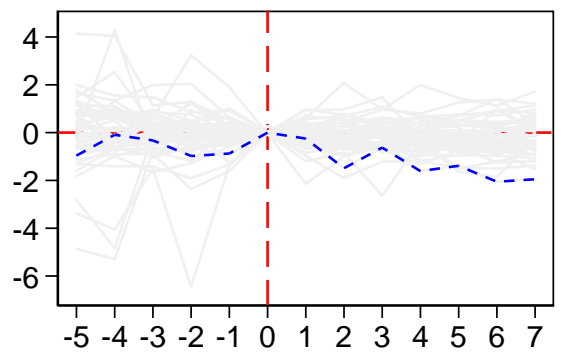

Panel C: 20-24

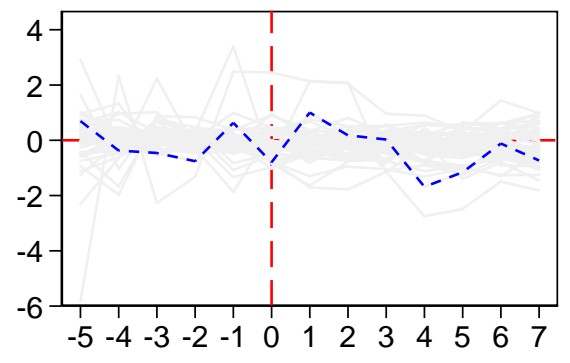

Panel E: 35-44

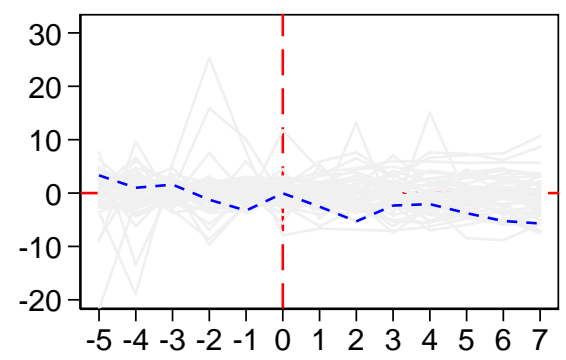

Panel B: 15-19

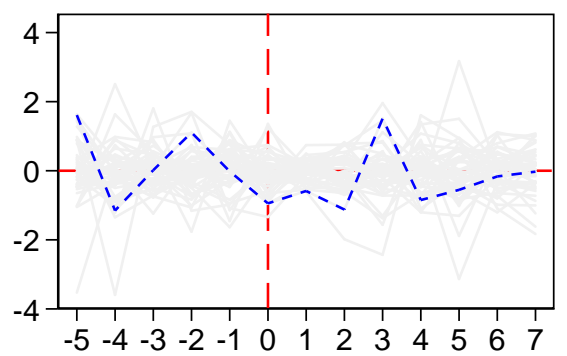

Panel D: 25-34

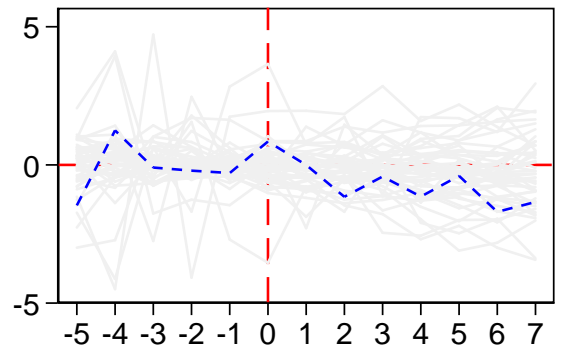

Notes: This figure shows the difference in birth spacing between Alaska and its synthetic control (dashed series), and the differences for all placebo states with respect to its corresponding synthetic controls (gray series). The x-axis measures periods, in years, before and after the introduction of APFD. The year APFD was introduced, 1982, is marked by a vertical line at period zero. The y-axis measures the average number of months between two live births for a woman in the respective age group. 
Figure 5: Alaska and Synthetic Control Trend, and a Comparison of Effects with Placebos, Abortion Rate
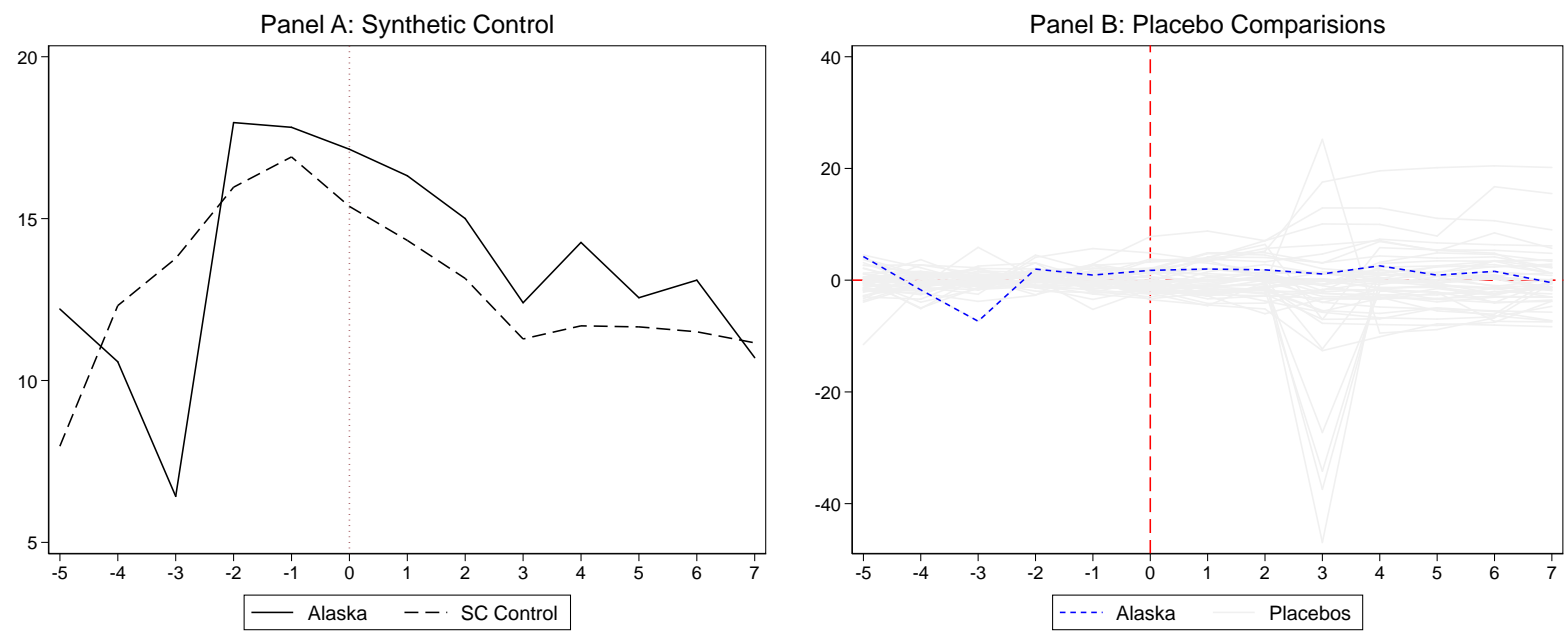

Notes: Panel A of this figure shows the trends in abortion rate for Alaska and its respective synthetic controls. Panel B shows the difference in fertility rates between Alaska and its synthetic control (dashed series), and the differences for all placebo states with respect to its corresponding synthetic controls (gray series). The states and their corresponding weights used for the construction of the synthetic control for Panel A are reported in Table A.1. The x-axis measures periods, in years, before and after the introduction of APFD. The year APFD was introduced, 1982, is marked by a vertical line at period zero. The y-axis measures the number of abortions per 1000 women in the respective age group. 
Table 1: Annual Per Capita APFD Disbursement

\begin{tabular}{cccc}
\hline Year & Fund Amount (in 2018 USD) & Year & Fund Amount (in 2018 USD) \\
\hline 1982 & $2,602.15$ & 2001 & $2,623.48$ \\
1983 & 973.54 & 2002 & $2,150.61$ \\
1984 & 800.67 & 2003 & $1,511.50$ \\
1985 & 942.82 & 2004 & $1,222.75$ \\
1986 & $1,274.46$ & 2005 & $1,087.44$ \\
1987 & $1,565.42$ & 2006 & $1,378.80$ \\
1988 & $1,755.27$ & 2007 & $2,003.12$ \\
1989 & $1,768.20$ & 2008 & $2,413.07$ \\
1990 & $1,830.24$ & 2009 & $1,527.45$ \\
1991 & $1,717.08$ & 2010 & $1,475.16$ \\
1992 & $1,639.16$ & 2011 & $1,310.58$ \\
1993 & $1,649.94$ & 2012 & 960.27 \\
1994 & $1,667.10$ & 2013 & 970.12 \\
1995 & $1,631.70$ & 2014 & $1,998.37$ \\
1996 & $1,809.57$ & 2015 & $2,195.17$ \\
1997 & $2,028.48$ & 2016 & $1,069.27$ \\
1998 & $2,373.78$ & 2017 & $1,126.87$ \\
1999 & $2,667.58$ & 2018 & $1,600.00$ \\
2000 & $2,863.76$ & & \\
\hline \hline
\end{tabular}

Note: The amounts presented here are expressed in 2018 USD. Source: Alaska Department of Revenue Permanent Fund Dividend Division (2019). 
Table 2: Descriptive Statistics, Fertility Rate

\begin{tabular}{|c|c|c|c|c|c|c|c|c|c|c|}
\hline & (1) & (2) & (3) & (4) & (5) & (6) & (7) & (8) & (9) & (10) \\
\hline & \multicolumn{2}{|c|}{$15-44$} & \multicolumn{2}{|c|}{$15-19$} & \multicolumn{2}{|c|}{$20-24$} & \multicolumn{2}{|c|}{$25-34$} & \multicolumn{2}{|c|}{$35-44$} \\
\hline Year & Alaska & US & Alaska & US & Alaska & US & Alaska & US & Alaska & US \\
\hline 1976 & 79.84 & 67.74 & 56.47 & 54.42 & 154.80 & 116.93 & 89.37 & 85.44 & 14.33 & 12.19 \\
\hline 1977 & 82.46 & 69.77 & 61.74 & 54.51 & 156.72 & 119.77 & 91.33 & 88.81 & 16.04 & 12.37 \\
\hline 1978 & 84.92 & 68.31 & 59.77 & 52.96 & 158.18 & 116.35 & 97.89 & 87.83 & 16.70 & 12.29 \\
\hline 1979 & 86.33 & 70.08 & 58.46 & 53.82 & 160.42 & 119.09 & 101.72 & 90.46 & 15.93 & 12.66 \\
\hline 1980 & 89.79 & 70.82 & 63.88 & 54.58 & 167.65 & 121.25 & 105.21 & 90.69 & 16.99 & 12.68 \\
\hline 1981 & 91.94 & 69.73 & 65.41 & 53.68 & 180.76 & 117.81 & 108.02 & 89.75 & 17.79 & 12.56 \\
\hline 1982 & 95.46 & 69.54 & 63.81 & 53.73 & 204.39 & 117.49 & 112.11 & 90.74 & 19.98 & 13.45 \\
\hline 1983 & 93.16 & 67.62 & 58.69 & 52.46 & 204.82 & 113.36 & 111.69 & 89.50 & 19.09 & 13.67 \\
\hline 1984 & 92.64 & 66.88 & 60.97 & 50.90 & 198.37 & 112.44 & 112.79 & 89.86 & 21.52 & 14.04 \\
\hline 1985 & 93.07 & 67.04 & 55.98 & 50.83 & 193.01 & 113.20 & 119.36 & 91.09 & 22.37 & 14.57 \\
\hline 1986 & 87.13 & 65.63 & 52.87 & 49.37 & 178.43 & 112.03 & 113.87 & 90.44 & 21.89 & 14.81 \\
\hline 1987 & 85.61 & 65.40 & 56.12 & 49.39 & 166.95 & 111.87 & 115.22 & 91.37 & 22.77 & 15.42 \\
\hline 1988 & 82.09 & 66.35 & 55.63 & 51.36 & 161.10 & 113.43 & 110.83 & 93.42 & 23.56 & 16.20 \\
\hline
\end{tabular}

Notes: This table presents the average annual fertility rate in Alaska and US excluding Alaska by various women's age groups. Fertility rate for the 15-44 population is defined as the total annual births per 1000 women between the ages of 15 and 44 . Fertility rates for other age groups are similarly normalized per 1000 women in that age group. Source: Authors' calculation using public use Natality files. 
Table 3: SC Pre-Treatment Balance Table, Fertility Rate

\begin{tabular}{|c|c|c|c|c|c|c|}
\hline & (1) & (2) & (3) & $(4)$ & (5) & (6) \\
\hline \multirow[t]{2}{*}{ Age Group } & \multicolumn{2}{|c|}{$15-44$} & \multicolumn{2}{|c|}{$15-19$} & \multicolumn{2}{|c|}{$20-24$} \\
\hline & Alaska & SC Control & Alaska & SC Control & Alaska & SC Control \\
\hline Fertility Rate & 87.11 & 86.93 & 61.36 & 61.27 & 168.99 & 168.84 \\
\hline FLP Rate & 57.54 & 60.58 & 57.54 & 59.64 & 57.54 & 60.01 \\
\hline Share Female & 57.00 & 48.74 & 57.00 & 48.17 & 57.00 & 49.31 \\
\hline Share White & 75.97 & 82.63 & 75.97 & 74.90 & 75.97 & 96.45 \\
\hline Share Rural & 0.43 & 0.29 & 0.41 & 0.65 & 0.44 & 0.16 \\
\hline Share LHS & 20.25 & 22.62 & 72.15 & 72.80 & 12.78 & 12.83 \\
\hline Share HS & 42.45 & 40.14 & 24.17 & 21.87 & 53.94 & 48.81 \\
\hline \multirow[t]{3}{*}{ GDP per capita (in \$) } & 14674 & 10399 & 14674 & 10764 & 14674 & 10330 \\
\hline & & & \multicolumn{2}{|c|}{$25-34$} & \multicolumn{2}{|c|}{$35-44$} \\
\hline & & & Alaska & SC Control & Alaska & SC Control \\
\hline Fertility Rate & & & 100.81 & 100.71 & 16.82 & 16.82 \\
\hline FLP Rate & & & 57.54 & 61.24 & 57.54 & 61.27 \\
\hline Share Female & & & 57.00 & 47.83 & 57.00 & 48.01 \\
\hline Share White & & & 75.97 & 67.80 & 75.97 & 64.40 \\
\hline Share Rural & & & 0.43 & 0.48 & 0.40 & 0.54 \\
\hline Share LHS & & & 6.79 & 9.05 & 15.03 & 16.41 \\
\hline Share HS & & & 40.76 & 38.00 & 40.00 & 38.73 \\
\hline GDP per capita (in \$) & & & 14674 & 10546 & 14674 & 10536 \\
\hline
\end{tabular}

Notes: This table presents the pre-treatment average statistics for each variable used in the SC methodology. The variables are averaged over the years 1976-1982. Column (1) reports statistics for the actual Alaska series, while columns (2), (3) and (4) report statistics for the synthetic counterfactual series for fertility rate, birth spacing, and abortion rate. The statistics reported here are for females in the 15-44 age group. Abbreviations: FLP - Female Labor Force Participation; LHS - less than high school degree; HS - high school degree. 
Table 4: SC Estimates, Fertility Rate

\begin{tabular}{|c|c|c|c|c|c|}
\hline & (1) & (2) & (3) & $(4)$ & (5) \\
\hline Fertility Rate & $15-44$ & $15-19$ & $20-24$ & $25-34$ & $35-44$ \\
\hline $\begin{array}{l}\text { Average Effect Size } \\
\text { p-value }\end{array}$ & $\begin{array}{l}11.261 \\
{[0.020]}\end{array}$ & $\begin{array}{c}0.487 \\
{[0.746]}\end{array}$ & $\begin{array}{l}20.277 \\
{[0.034]}\end{array}$ & $\begin{array}{l}14.143 \\
{[0.026]}\end{array}$ & $\begin{array}{c}2.756 \\
{[0.091]}\end{array}$ \\
\hline Number of Placebos & 357 & 357 & 357 & 357 & 357 \\
\hline Pre-Preriod RMSPE & 1.965 & 1.653 & 4.493 & 5.575 & 0.786 \\
\hline RMSPE Percentile & 0.847 & 0.584 & 0.894 & 0.951 & 0.802 \\
\hline
\end{tabular}

Notes: This table presents estimates of SC studies with fertility rate as the outcome variable. The estimates are averaged over the post-treatment period: $\hat{\theta}_{1}=\sum_{t=T_{0}+1}^{T} \frac{1}{\left(T-\left(T_{0}+1\right)\right)} \hat{\theta}_{1, t} \cdot p$-value is calculated using permutation test described in equation 13. Root Mean Square Prediction Error (RMSPE) is calculated for Alaska for the years 1976-1982. RMSPE percentile is based on the RMSPE for each of the 50 placebo studies. 
Table 5: Descriptive Statistics: Birth Spacing

\begin{tabular}{cccccccccccc}
\hline \multicolumn{1}{c}{$(1)$} & $(2)$ & $(3)$ & $(4)$ & $(5)$ & $(6)$ & $(7)$ & $(8)$ & $(9)$ & $(10)$ \\
\hline \multirow{2}{*}{ Year } & Alaska & US & \multicolumn{2}{c}{$15-19$} & \multicolumn{2}{c}{$20-24$} & \multicolumn{2}{c}{$25-34$} & \multicolumn{2}{c}{$35-44$} \\
& Alaska & US & Alaska & US & Alaska & US & Alaska & US \\
\hline 1976 & 42.73 & 44.70 & 24.01 & 23.10 & 32.98 & 33.44 & 46.00 & 49.54 & 76.94 & 80.04 \\
1977 & 43.78 & 44.94 & 22.76 & 23.24 & 31.95 & 33.73 & 48.44 & 49.73 & 75.51 & 80.42 \\
1978 & 43.32 & 44.90 & 23.19 & 23.17 & 31.41 & 33.54 & 46.98 & 49.54 & 76.94 & 81.11 \\
1979 & 42.41 & 44.76 & 23.94 & 23.16 & 30.94 & 33.41 & 46.60 & 49.08 & 73.01 & 81.69 \\
1980 & 42.31 & 44.50 & 22.98 & 22.68 & 31.84 & 33.04 & 45.94 & 48.85 & 71.11 & 80.52 \\
1981 & 42.42 & 44.18 & 21.50 & 22.56 & 30.19 & 32.54 & 46.08 & 48.40 & 73.53 & 79.35 \\
1982 & 42.57 & 44.00 & 21.61 & 22.45 & 31.36 & 32.32 & 45.78 & 47.84 & 70.28 & 78.20 \\
1983 & 41.70 & 44.20 & 21.12 & 22.51 & 30.85 & 32.41 & 44.47 & 47.78 & 67.51 & 77.46 \\
1984 & 42.37 & 44.28 & 23.83 & 22.63 & 31.07 & 32.65 & 44.46 & 47.48 & 69.91 & 75.50 \\
1985 & 42.08 & 44.67 & 22.29 & 22.57 & 29.78 & 32.87 & 44.10 & 47.71 & 69.74 & 75.35 \\
1986 & 43.06 & 44.94 & 21.58 & 22.41 & 30.28 & 32.82 & 45.33 & 47.88 & 68.19 & 74.40 \\
1987 & 43.05 & 45.21 & 22.27 & 22.42 & 31.54 & 32.70 & 44.71 & 48.07 & 66.15 & 73.40 \\
1988 & 43.04 & 45.46 & 22.63 & 22.30 & 30.95 & 32.63 & 44.73 & 48.25 & 64.21 & 72.95 \\
\hline \hline
\end{tabular}

Notes: This table presents the average annual birth spacing in Alaska and US excluding Alaska for various women's age groups. Birth spacing is measured as the average number of months between births of two children for women in the respective age groups. Source: Authors' calculation using public use Natality files. 
Table 6: SC Pre-Treatment Balance Table, Birth Spacing

\begin{tabular}{|c|c|c|c|c|c|c|}
\hline & (1) & $(2)$ & (3) & $(4)$ & (5) & (6) \\
\hline \multirow[t]{2}{*}{ Age Group } & \multicolumn{2}{|c|}{$15-44$} & \multicolumn{2}{|c|}{$15-19$} & \multicolumn{2}{|c|}{$20-24$} \\
\hline & Alaska & SC Control & Alaska & SC Control & Alaska & SC Control \\
\hline Birth Spacing & 42.60 & 42.79 & 22.86 & 22.85 & 31.52 & 31.53 \\
\hline FLP Rate & 57.54 & 61.52 & 57.54 & 60.04 & 57.54 & 59.83 \\
\hline Share Female & 57.00 & 48.28 & 57.00 & 48.66 & 57.00 & 47.89 \\
\hline Share White & 75.97 & 75.66 & 75.97 & 76.62 & 75.97 & 76.98 \\
\hline Share Rural & 0.43 & 0.70 & 0.41 & 0.49 & 0.44 & 0.54 \\
\hline Share LHS & 20.25 & 21.05 & 72.15 & 71.98 & 12.78 & 12.44 \\
\hline Share HS & 42.45 & 41.07 & 24.17 & 22.97 & 53.94 & 48.23 \\
\hline \multirow[t]{3}{*}{ GDP per capita (in \$) } & 14674 & 10037 & 14674 & 10469 & 14674 & 10550 \\
\hline & & & \multicolumn{2}{|c|}{$25-34$} & \multicolumn{2}{|c|}{$35-44$} \\
\hline & & & Alaska & SC Control & Alaska & SC Control \\
\hline Birth Spacing & & & 46.55 & 46.50 & 73.90 & 74.06 \\
\hline FLP Rate & & & 57.54 & 60.75 & 57.54 & 58.77 \\
\hline Share Female & & & 57.00 & 48.74 & 57.00 & 47.70 \\
\hline Share White & & & 75.97 & 77.71 & 75.97 & 74.10 \\
\hline Share Rural & & & 0.43 & 0.74 & 0.40 & 0.77 \\
\hline Share LHS & & & 6.79 & 8.09 & 15.03 & 16.35 \\
\hline Share HS & & & 40.76 & 37.06 & 40.00 & 35.91 \\
\hline GDP per capita (in $\$$ ) & & & 14674 & 10054 & 14674 & 10712 \\
\hline
\end{tabular}

Notes: This table presents the pre-treatment average statistics for each variable used in the SC methodology. The variables are averaged over the years 1976-1982. Column (1) reports statistics for the actual Alaska series, while columns (2), (3) and (4) report statistics for the synthetic counterfactual series for fertility rate, birth spacing, and abortion rate. The statistics reported here are for females in the 15-44 age group. Abbreviations: FLP - Female Labor Force Participation; LHS - less than high school degree; HS - high school degree. 
Table 7: SC Estimates, Birth Spacing

\begin{tabular}{|c|c|c|c|c|c|}
\hline & (1) & (2) & (3) & (4) & (5) \\
\hline Birth Spacing & $15-44$ & $15-19$ & $20-24$ & $25-34$ & $35-44$ \\
\hline $\begin{array}{l}\text { Average Effect Size } \\
\text { p-value }\end{array}$ & $\begin{array}{l}-0.124 \\
{[0.580]}\end{array}$ & $\begin{array}{l}-0.255 \\
{[0.363]}\end{array}$ & $\begin{array}{l}-0.353 \\
{[0.423]}\end{array}$ & $\begin{array}{l}-0.879 \\
{[0.463]}\end{array}$ & $\begin{array}{l}-3.847 \\
{[0.280]}\end{array}$ \\
\hline Number of Placebos & 357 & 357 & 357 & 357 & 357 \\
\hline Pre-Preriod RMSPE & 0.403 & 1.004 & 0.638 & 0.871 & 2.117 \\
\hline RMSPE Percentile & 0.507 & 0.862 & 0.787 & 0.753 & 0.520 \\
\hline
\end{tabular}

Notes: This table presents estimates of SC studies with birth spacing as the outcome variable. The estimates are averaged over the post-treatment period: $\hat{\theta}_{1}=\sum_{t=T_{0}+1}^{T} \frac{1}{\left(T-\left(T_{0}+1\right)\right)} \hat{\theta}_{1, t} \cdot p$-value is calculated using permutation test described in equation 13. Root Mean Square Prediction Error (RMSPE) is calculated for Alaska for the years 1976-1982. RMSPE percentile is based on the RMSPE for each of the 50 placebo studies. 
Table 8: Descriptive Statistics, Abortion Rate

\begin{tabular}{|c|c|c|}
\hline & (1) & (2) \\
\hline Year & Alaska & US \\
\hline 1976 & 12.21 & 18.69 \\
\hline 1977 & 10.58 & 19.66 \\
\hline 1978 & 6.42 & 21.44 \\
\hline 1979 & 17.97 & 22.72 \\
\hline 1980 & 17.82 & 23.19 \\
\hline 1981 & 17.14 & 22.71 \\
\hline 1982 & 16.33 & 22.29 \\
\hline 1983 & 15.00 & 21.41 \\
\hline 1984 & 12.40 & 25.57 \\
\hline 1985 & 14.27 & 20.54 \\
\hline 1986 & 12.56 & 20.06 \\
\hline 1987 & 13.10 & 20.32 \\
\hline 1988 & 10.71 & 20.62 \\
\hline
\end{tabular}

Notes: This table presents the annual abortion rate in Alaska and in the US excluding Alaska for the 15-44 women's age group. Abortion rates are measured as the number of reported abortions per 1000 women between the ages of 15 and 44 . Source: Abortion Surveillance Reports, Centers for Disease Control. 
Table 9: SC Pre-Treatment Balance Table, Abortion Rate

\begin{tabular}{lccc}
\hline & $(1)$ & $(2)$ \\
\hline & Alaska & & SC Control \\
\cline { 2 - 2 } Abortion Rate & 14.07 & & 14.09 \\
FLP Rate & 57.54 & & 60.12 \\
Share Female & 57.00 & & 49.31 \\
Share White & 75.97 & & 95.49 \\
Share Rural & 0.43 & & 0.37 \\
Share LHS & 20.25 & & 23.84 \\
Share HS & 42.45 & & 41.67 \\
GDP per capita (in \$) & 14674 & & 10448 \\
\hline \hline
\end{tabular}

Notes: This table presents the pre-treatment average statistics for each variable used in the SC methodology. The variables are averaged over the years 1976-1982. Column (1) reports statistics for the actual Alaska series, while columns (2), (3) and (4) report statistics for the synthetic counterfactual series for fertility rate, birth spacing, and abortion rate. The statistics reported here are for females in the 15-44 age group. Abbreviations: FLP - Female Labor Force Participation; LHS - less than high school degree; HS - high school degree.

Table 10: SC Estimates, Abortion Rate

\begin{tabular}{lc}
\hline & $(1)$ \\
& $15-44$ \\
\cline { 2 - 2 } Average Effect Size & 1.368 \\
p-value & {$[0.657]$} \\
& \\
Number of Placebos & 357 \\
Pre-Preriod RMSPE & 3.729 \\
RMSPE Percentile & 0.856 \\
\hline \hline
\end{tabular}

Notes: This table presents estimates of SC studies with abortion rate as the outcome variable. The estimates are averaged over the post-treatment period: $\hat{\theta}_{1}=\sum_{t=T_{0}+1}^{T} \frac{1}{\left(T-\left(T_{0}+1\right)\right)} \hat{\theta}_{1, t} \cdot p$-value is calculated using permutation test described in equation 13. Root Mean Square Prediction Error (RMSPE) is calculated for Alaska for the years 1976-1982. RMSPE percentile is based on the RMSPE for each of the 50 placebo studies. 
Table 11: DiD Estimates, Fertility Rate

\begin{tabular}{|c|c|c|c|c|c|c|}
\hline & (1) & $(2)$ & (3) & (4) & (5) & (6) \\
\hline Panel A: 15-44 & \multicolumn{4}{|c|}{ DiD with All States } & \multicolumn{2}{|c|}{ DiD with SC states } \\
\hline DD Estimate & $\begin{array}{c}6.484^{* * *} \\
(0.702)\end{array}$ & $\begin{array}{c}6.484^{* * *} \\
(0.707)\end{array}$ & $\begin{array}{c}6.484^{* * *} \\
(0.736)\end{array}$ & $\begin{array}{c}6.901^{* * *} \\
(1.265)\end{array}$ & $\begin{array}{c}11.597^{* *} \\
(4.155)\end{array}$ & $\begin{array}{c}11.597^{* * *} \\
(1.456)\end{array}$ \\
\hline R-squared & 0.079 & 0.092 & 0.353 & 0.911 & 0.396 & 0.963 \\
\hline Dep Var Mean & 68.46 & 68.46 & 68.46 & 68.46 & 85.32 & 85.32 \\
\hline \multicolumn{7}{|l|}{ Panel B: 15-19 } \\
\hline DD Estimate & $\begin{array}{l}-0.385 \\
(0.595)\end{array}$ & $\begin{array}{l}-0.385 \\
(0.600)\end{array}$ & $\begin{array}{l}-0.385 \\
(0.624)\end{array}$ & $\begin{array}{c}-0.158 \\
(1.385)\end{array}$ & $\begin{array}{c}1.249 \\
(2.591)\end{array}$ & $\begin{array}{c}1.249 \\
(1.014)\end{array}$ \\
\hline R-squared & 0.016 & 0.023 & 0.483 & 0.950 & 0.290 & 0.947 \\
\hline Dep Var Mean & 52.593 & 52.593 & 52.593 & 52.593 & 58.871 & 58.871 \\
\hline \multicolumn{7}{|l|}{ Panel C: 20-24 } \\
\hline DD Estimate & $\begin{array}{c}28.765^{* * *} \\
(1.045)\end{array}$ & $\begin{array}{c}28.765^{* * *} \\
(1.054)\end{array}$ & $\begin{array}{c}28.765^{* * *} \\
(1.096)\end{array}$ & $\begin{array}{c}28.292^{* * *} \\
(1.354)\end{array}$ & $\begin{array}{l}23.426^{* *} \\
(10.013)\end{array}$ & $\begin{array}{c}23.426^{* * *} \\
(2.831)\end{array}$ \\
\hline R-squared & 0.135 & 0.141 & 0.428 & 0.953 & 0.381 & 0.975 \\
\hline Dep Var Mean & 116.949 & 116.949 & 116.949 & 116.949 & 171.082 & 171.082 \\
\hline \multicolumn{7}{|l|}{ Panel D: 25-34 } \\
\hline DD Estimate & $\begin{array}{c}12.684^{* * *} \\
(0.903)\end{array}$ & $\begin{array}{c}12.684^{* * *} \\
(0.911)\end{array}$ & $\begin{array}{c}12.684^{* * *} \\
(0.948)\end{array}$ & $\begin{array}{c}12.964^{* * *} \\
(1.809)\end{array}$ & $\begin{array}{c}15.563^{* * *} \\
(3.481)\end{array}$ & $\begin{array}{c}15.563^{* * *} \\
(2.928)\end{array}$ \\
\hline R-squared & 0.038 & 0.049 & 0.441 & 0.923 & 0.723 & 0.899 \\
\hline Dep Var Mean & 90.285 & 90.285 & 90.285 & 90.285 & 103.475 & 103.475 \\
\hline \multicolumn{7}{|l|}{ Panel E: 35-44 } \\
\hline DD Estimate & $\begin{array}{c}3.164^{* * *} \\
(0.311)\end{array}$ & $\begin{array}{c}3.164^{* * *} \\
(0.313)\end{array}$ & $\begin{array}{c}3.164^{* * *} \\
(0.326)\end{array}$ & $\begin{array}{c}2.472^{* * *} \\
(0.292)\end{array}$ & $\begin{array}{c}2.985^{\star * *} \\
(0.878)\end{array}$ & $\begin{array}{c}2.985^{* * *} \\
(0.498)\end{array}$ \\
\hline R-squared & 0.104 & 0.131 & 0.131 & & 0.810 & 0.967 \\
\hline Dep Var Mean & 13.716 & 13.716 & 13.716 & 13.716 & 18.497 & 18.497 \\
\hline $\mathrm{N}$ & 663 & 663 & 663 & 663 & 26 & 26 \\
\hline Time FE & & $\mathrm{x}$ & $\mathrm{x}$ & $\mathrm{x}$ & & $\mathrm{x}$ \\
\hline Control Variables & & & $\mathrm{x}$ & $\mathrm{x}$ & & \\
\hline State FE & & & & $\mathrm{x}$ & & \\
\hline Clustered SE & $\mathrm{x}$ & $\mathrm{x}$ & $\mathrm{x}$ & $\mathrm{x}$ & & \\
\hline
\end{tabular}

${ }^{*<0.10,{ }^{* *}<0.05,,^{* *}<0.01}$

Notes: DiD coefficients are calculated using years 1976-1988. Columns (1) - (4) presents results for DiD studies with unrestricted controls. In columns (5) and (6) the control states are restricted to the states with positive SC methodology weights. The list of these states are presented in Table A.1. List of control variables includes: share of female labor force participation, female share of less than high school education, share of female population aged 15-44, population growth rate, share of white race, and GDP per capita. 
Table 12: DiD Estimates, Birth Spacing

\begin{tabular}{|c|c|c|c|c|c|c|}
\hline & (1) & $(2)$ & (3) & (4) & (5) & (6) \\
\hline Panel A: 15-44 & \multicolumn{4}{|c|}{ DiD with All States } & \multicolumn{2}{|c|}{ DiD with SC states } \\
\hline DD Estimate & $\begin{array}{c}-0.295^{*} \\
(0.148)\end{array}$ & $\begin{array}{l}-0.295^{*} \\
(0.149)\end{array}$ & $\begin{array}{l}-0.295^{*} \\
(0.155)\end{array}$ & $\begin{array}{c}-0.593^{\star *} \\
(0.249)\end{array}$ & $\begin{array}{l}-0.189 \\
(0.488)\end{array}$ & $\begin{array}{l}-0.189 \\
(0.265)\end{array}$ \\
\hline R-squared & 0.008 & 0.027 & 0.561 & 0.929 & 0.056 & 0.861 \\
\hline Dep Var Mean & 44.63 & 44.63 & 44.63 & 44.63 & 42.78 & 42.78 \\
\hline \multicolumn{7}{|l|}{ Panel B: 15-19 } \\
\hline DD Estimate & $\begin{array}{c}-0.360^{* * *} \\
(0.055)\end{array}$ & $\begin{array}{c}-0.360^{* * *} \\
(0.056)\end{array}$ & $\begin{array}{c}-0.360^{* * *} \\
(0.058)\end{array}$ & $\begin{array}{c}-0.701^{* * *} \\
(0.186)\end{array}$ & $\begin{array}{l}-0.354 \\
(0.569)\end{array}$ & $\begin{array}{l}-0.354 \\
(0.553)\end{array}$ \\
\hline R-squared & 0.084 & 0.023 & 0.272 & 0.606 & 0.231 & 0.644 \\
\hline Dep Var Mean & 22.705 & 22.705 & 22.705 & 22.705 & 22.636 & 22.636 \\
\hline \multicolumn{7}{|l|}{ Panel C: 20-24 } \\
\hline DD Estimate & $\begin{array}{l}-0.064 \\
(0.133)\end{array}$ & $\begin{array}{l}-0.064 \\
(0.134)\end{array}$ & $\begin{array}{l}-0.064 \\
(0.140)\end{array}$ & $\begin{array}{c}0.037 \\
(0.193)\end{array}$ & $\begin{array}{l}-0.272 \\
(0.549)\end{array}$ & $\begin{array}{l}-0.272 \\
(0.447)\end{array}$ \\
\hline R-squared & 0.041 & 0.063 & 0.462 & 0.877 & 0.223 & 0.716 \\
\hline Dep Var Mean & 32.897 & 32.897 & 32.897 & 32.897 & 31.321 & 31.321 \\
\hline \multicolumn{7}{|l|}{ Panel D: 25-34 } \\
\hline DD Estimate & $\begin{array}{c}-0.546^{* * *} \\
(0.172)\end{array}$ & $\begin{array}{c}-0.546^{* * *} \\
(0.174)\end{array}$ & $\begin{array}{c}-0.546^{* * *} \\
(0.181)\end{array}$ & $\begin{array}{c}-0.725^{\star * *} \\
(0.266)\end{array}$ & $\begin{array}{l}-0.407 \\
(0.554)\end{array}$ & $\begin{array}{l}-0.407 \\
(0.378)\end{array}$ \\
\hline R-squared & 0.031 & 0.038 & 0.687 & 0.952 & 0.649 & 0.915 \\
\hline Dep Var Mean & 48.417 & 48.417 & 48.417 & 48.417 & 45.786 & 45.786 \\
\hline \multicolumn{7}{|l|}{ Panel E: 35-44 } \\
\hline DD Estimate & $\begin{array}{c}-1.310^{* *} \\
(0.512)\end{array}$ & $\begin{array}{c}-1.310^{\star *} \\
(0.516)\end{array}$ & $\begin{array}{c}-1.310^{* *} \\
(0.537)\end{array}$ & $\begin{array}{c}-1.200^{\star *} \\
(0.531)\end{array}$ & $\begin{array}{c}-3.806^{* *} \\
(1.378)\end{array}$ & $\begin{array}{c}-3.806^{* * *} \\
(1.130)\end{array}$ \\
\hline R-squared & 0.103 & 0.130 & 0.593 & 0.853 & 0.730 & 0.914 \\
\hline Dep Var Mean & 77.590 & 77.590 & 77.590 & 77.590 & 71.931 & 71.931 \\
\hline $\mathrm{N}$ & 663 & 663 & 663 & 663 & 26 & 26 \\
\hline Time FE & & $\mathrm{x}$ & $\mathrm{x}$ & $\mathrm{x}$ & & $\mathrm{x}$ \\
\hline Control Variables & & & $\mathrm{x}$ & $\mathrm{x}$ & & \\
\hline State FE & & & & $\mathrm{x}$ & & \\
\hline Clustered SE & $\mathrm{X}$ & $\mathrm{x}$ & $\mathrm{X}$ & $\mathrm{x}$ & & \\
\hline
\end{tabular}

Notes: DiD coefficients are calculated using years 1976-1988. Columns (1) - (4) presents results for DiD studies with unrestricted controls. In columns (5) and (6) the control states are restricted to the states with positive SC methodology weights. The list of these states are presented in Table A.1. List of control variables includes: share of female labor force participation, female share of less than high school education, share of female population aged 15-44, population growth rate, share of white race, and GDP per capita. 
Table 13: DiD Estimates, Abortion Rate

\begin{tabular}{|c|c|c|c|c|c|c|}
\hline & (1) & (2) & (3) & (4) & (5) & (6) \\
\hline Panel A: 15-44 & \multicolumn{4}{|c|}{ DiD with All States } & \multicolumn{2}{|c|}{ DiD with SC states } \\
\hline DD Estimate & $\begin{array}{l}-0.352 \\
(1.133)\end{array}$ & $\begin{array}{l}-0.352 \\
(1.142)\end{array}$ & $\begin{array}{l}-0.352 \\
(1.188)\end{array}$ & $\begin{array}{l}-0.053 \\
(2.889)\end{array}$ & $\begin{array}{c}1.391 \\
(2.492)\end{array}$ & $\begin{array}{c}1.391 \\
(1.691)\end{array}$ \\
\hline R-squared & 0.003 & 0.010 & 0.470 & 0.846 & 0.047 & 0.786 \\
\hline Dep Var Mean & 21.32 & 21.32 & 21.32 & 21.32 & 13.36 & 13.36 \\
\hline $\mathrm{N}$ & 663 & 663 & 663 & 663 & 26 & 26 \\
\hline Time FE & & $\mathrm{x}$ & $\mathrm{x}$ & $\mathrm{x}$ & & $\mathrm{x}$ \\
\hline Control Variables & & & $\mathrm{x}$ & $\mathrm{x}$ & & \\
\hline State FE & & & & $\mathrm{x}$ & & \\
\hline Clustered SE & $\mathrm{x}$ & $\mathrm{x}$ & $\mathrm{x}$ & $\mathrm{x}$ & & \\
\hline
\end{tabular}

${ }^{\star}<0.10,^{* *}<0.05,{ }^{* *}<0.01$

Notes: DiD coefficients are calculated using years 1976-1988. Columns (1) - (4) presents results for DiD studies with unrestricted controls. In columns (5) and (6) the control states are restricted to the states with positive SC methodology weights. The list of these states are presented in Table A.1. List of control variables includes: share of female labor force participation, female share of less than high school education, share of female population aged 15-44, population growth rate, share of white race, and GDP per capita. 


\section{A Appendix}

Figure A.1: Raw Trends in Fertility Rate for Alaska and US Average (excluding Alaska)
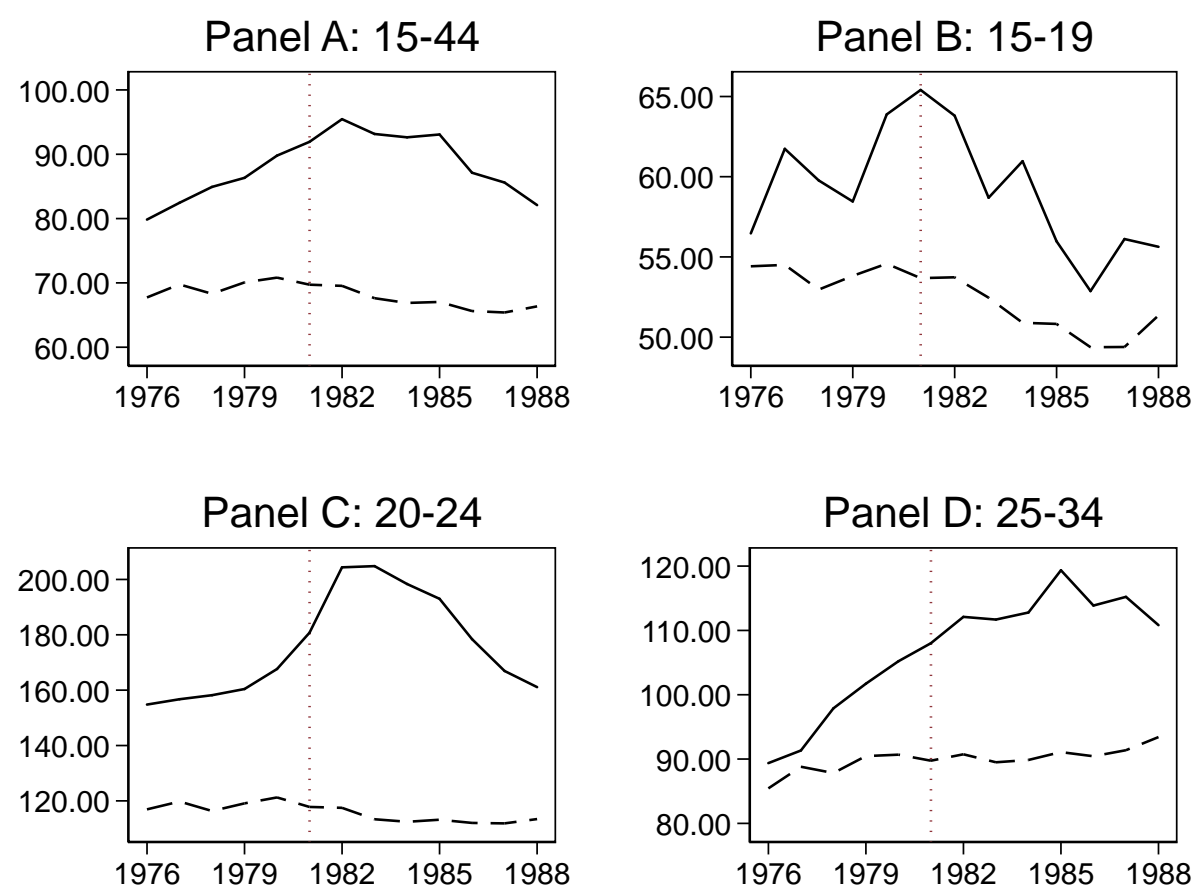

\section{Panel E: 35-44}

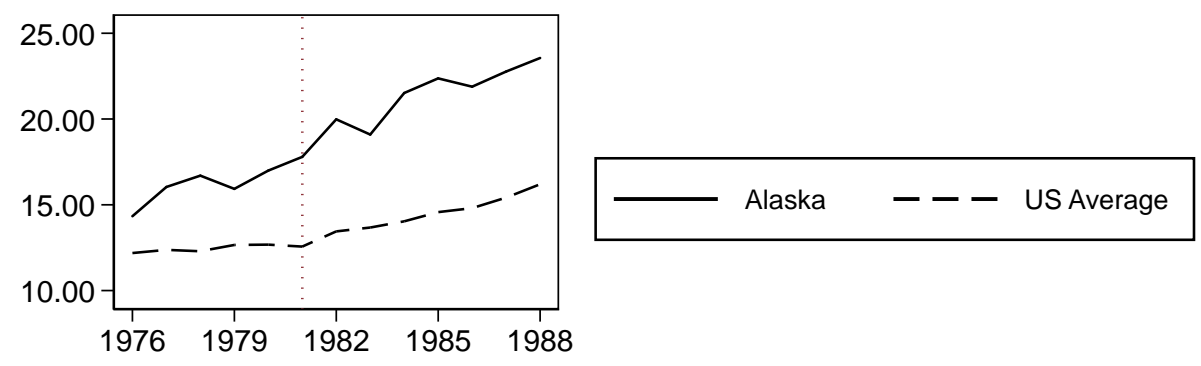

Notes: This figure shows the raw trends in fertility rate for various age group for Alaska (solid line) and for the US excluding Alaska (dashed line). Fertility Rate is calculated as the number of live births per 1000 women in the respective age group. The $\mathrm{x}$-axis measures periods, in years, before and after the introduction of APFD. The year APFD was introduced, 1982, is marked by a vertical line at period zero. Source: Natality Files, Vital Statistics. 
Figure A.2: Raw Trends in Birth Spacing for Alaska and US Average (excluding Alaska)

\section{Panel A: 15-44}

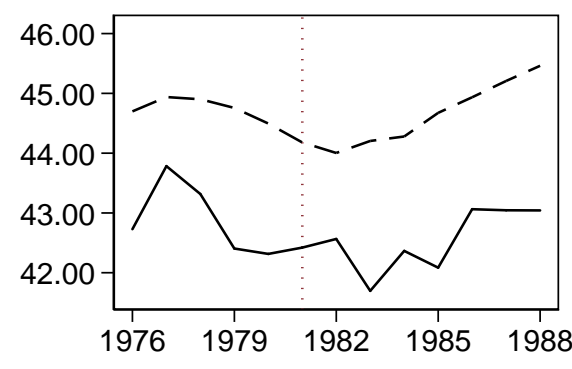

Panel C: $20-24$

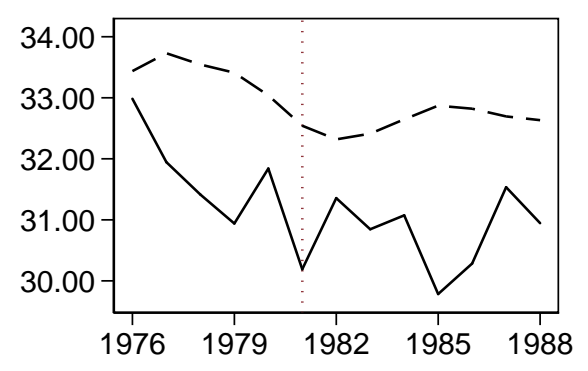

Panel E: 35-44

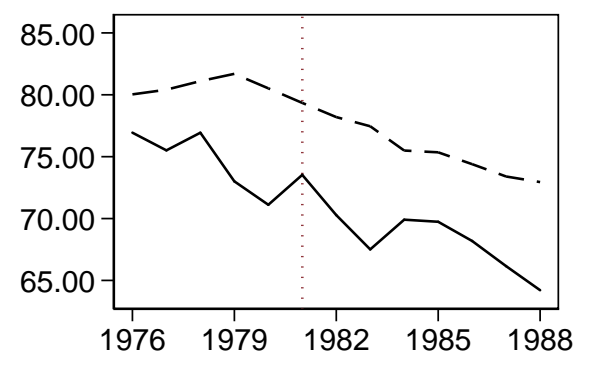

Panel B: 15-19

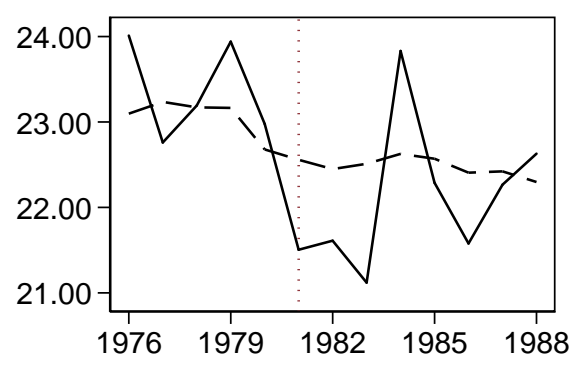

Panel D: 25-34

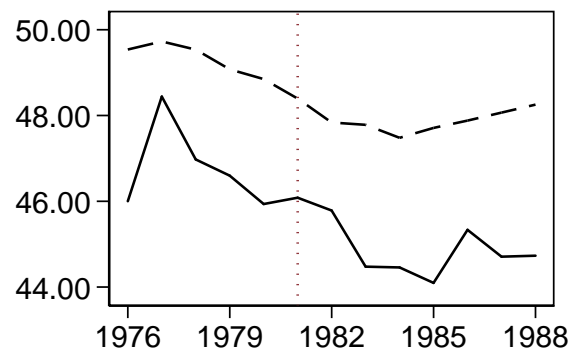

Notes: This figure shows the raw trends in birth spacing for various age group for Alaska (solid line) and for the US excluding Alaska (dashed line). Birth Spacing is calculated as the number of months between two live births for women in the respective age group. The x-axis measures periods, in years, before and after the introduction of APFD. The year APFD was introduced, 1982, is marked by a vertical line at period zero. Source: Natality Files, Vital Statistics. 
Figure A.3: Raw Trends in Abortion Rate for Alaska and US Average (excluding Alaska)

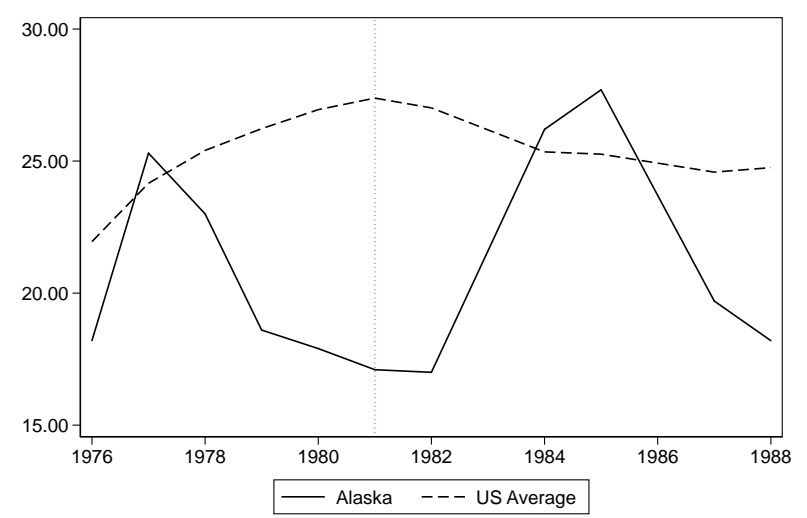

Notes: This figure shows the raw trends in abortion rate for various age group for Alaska (solid line) and for the US excluding Alaska (dashed line). Abortion rate is calculated as the number of abortions per 1000 women in the respective age group. The $\mathrm{x}$-axis measures periods, in years, before and after the introduction of APFD. The year APFD was introduced, 1982, is marked by a vertical line at period zero. Source: Natality Files, Vital Statistics. 
Table A.1: Synthetic Control Weights

\begin{tabular}{|c|c|c|c|c|c|}
\hline \multirow[b]{2}{*}{ State } & \multicolumn{5}{|c|}{ Panel A: Fertility Rate } \\
\hline & $15-44$ & $15-19$ & $20-24$ & $25-34$ & $35-44$ \\
\hline California & 0.000 & 0.489 & 0.000 & 0.000 & 0.000 \\
\hline Connecticut & 0.000 & 0.000 & 0.000 & 0.031 & 0.000 \\
\hline $\mathrm{DC}$ & 0.021 & 0.212 & 0.051 & 0.051 & 0.183 \\
\hline Hawaii & 0.239 & 0.022 & 0.000 & 0.389 & 0.273 \\
\hline Utah & 0.000 & 0.000 & 0.000 & 0.000 & 0.081 \\
\hline \multirow[t]{3}{*}{ Wyoming } & 0.741 & 0.277 & 0.949 & 0.529 & 0.462 \\
\hline & \multicolumn{5}{|c|}{ Panel B: Birth-Spacing } \\
\hline & $15-44$ & $15-19$ & $20-24$ & $25-34$ & $35-44$ \\
\hline California & 0.000 & 0.000 & 0.000 & 0.000 & 0.642 \\
\hline Colorado & 0.281 & 0.000 & 0.000 & 0.294 & 0.000 \\
\hline $\mathrm{DC}$ & 0.000 & 0.000 & 0.000 & 0.031 & 0.055 \\
\hline Hawaii & 0.295 & 0.202 & 0.285 & 0.241 & 0.175 \\
\hline Maryland & 0.000 & 0.342 & 0.000 & 0.000 & 0.000 \\
\hline Minnesota & 0.341 & 0.000 & 0.000 & 0.023 & 0.000 \\
\hline Nevada & 0.000 & 0.000 & 0.185 & 0.000 & 0.013 \\
\hline New Jersey & 0.000 & 0.000 & 0.025 & 0.000 & 0.000 \\
\hline \multirow[t]{2}{*}{ Wyoming } & 0.083 & 0.457 & 0.505 & 0.410 & 0.115 \\
\hline & \multicolumn{5}{|c|}{ Panel C: Abortion Rate } \\
\hline State & $15-44$ & & & & \\
\hline Nevada & 0.326 & & & & \\
\hline Wyoming & 0.674 & & & & \\
\hline
\end{tabular}

Notes: This table presents the weights used to construct the synthetic control for Alaska. Column (1) gives weights for synthetic Alaska for the females aged 15-44. Panels (2) - (4) gives weights by age groups 15-19, 20-24, 25-34, and 35-44. Panel A provides weights for controls for study based on fertility rate, Panel B does this for birth spacing, and Panel C does the same for abortion rate. Technical source: Quistorff and Galiani (2017). 
Table A.2: Birth Spacing Data

\begin{tabular}{cccccc}
\hline Year & Nonreporting states & Missing data & Plural deliveries & Coded $<9$ months & Share of births used \\
\hline 1976 & $19.29 \%$ & $3.15 \%$ & $0.63 \%$ & $0.14 \%$ & $76.79 \%$ \\
1977 & $18.27 \%$ & $3.23 \%$ & $0.63 \%$ & $0.12 \%$ & $77.75 \%$ \\
1978 & $0.00 \%$ & $10.39 \%$ & $0.72 \%$ & $0.15 \%$ & $88.74 \%$ \\
1979 & $0.00 \%$ & $9.75 \%$ & $0.73 \%$ & $0.17 \%$ & $89.35 \%$ \\
1980 & $0.00 \%$ & $9.73 \%$ & $0.74 \%$ & $0.15 \%$ & $89.38 \%$ \\
1981 & $0.00 \%$ & $8.41 \%$ & $0.77 \%$ & $0.13 \%$ & $90.69 \%$ \\
1982 & $0.00 \%$ & $8.25 \%$ & $0.80 \%$ & $0.15 \%$ & $90.80 \%$ \\
1983 & $0.00 \%$ & $8.23 \%$ & $0.82 \%$ & $0.15 \%$ & $90.80 \%$ \\
1984 & $0.00 \%$ & $8.40 \%$ & $0.83 \%$ & $0.14 \%$ & $90.63 \%$ \\
1985 & $0.00 \%$ & $8.11 \%$ & $0.86 \%$ & $0.13 \%$ & $90.90 \%$ \\
1986 & $0.00 \%$ & $8.20 \%$ & $0.88 \%$ & $0.14 \%$ & $90.78 \%$ \\
1987 & $0.00 \%$ & $7.93 \%$ & $0.90 \%$ & $0.15 \%$ & $91.02 \%$ \\
1988 & $0.00 \%$ & $8.45 \%$ & $0.92 \%$ & $0.14 \%$ & $90.49 \%$ \\
\hline
\end{tabular}

Notes: Share of states that did not report data for birth spacing is reported in Non-reporting states. This variable is coded in Natality files as: "Not applicable." Because of this, we exclude 1976 and 1977 from our analysis for births spacing. Missing data reports the fraction of birth spacing data that is missing. Plural deliveries reports the percentage of non-singleton births. Coded $<9$ months are the share of births with birth spacing recorded as less than 9 months; we code this as missing. Finally, Share of births used reports the percentage of data used for birth spacing analysis out of all eligible births (two or more). 


\section{B Sensitivity Checks: Using the last year before intervention as the only matching outcome variable}

Figure B.1: Alaska and Synthetic Control Trends, Fertility Rate using Last Year Method
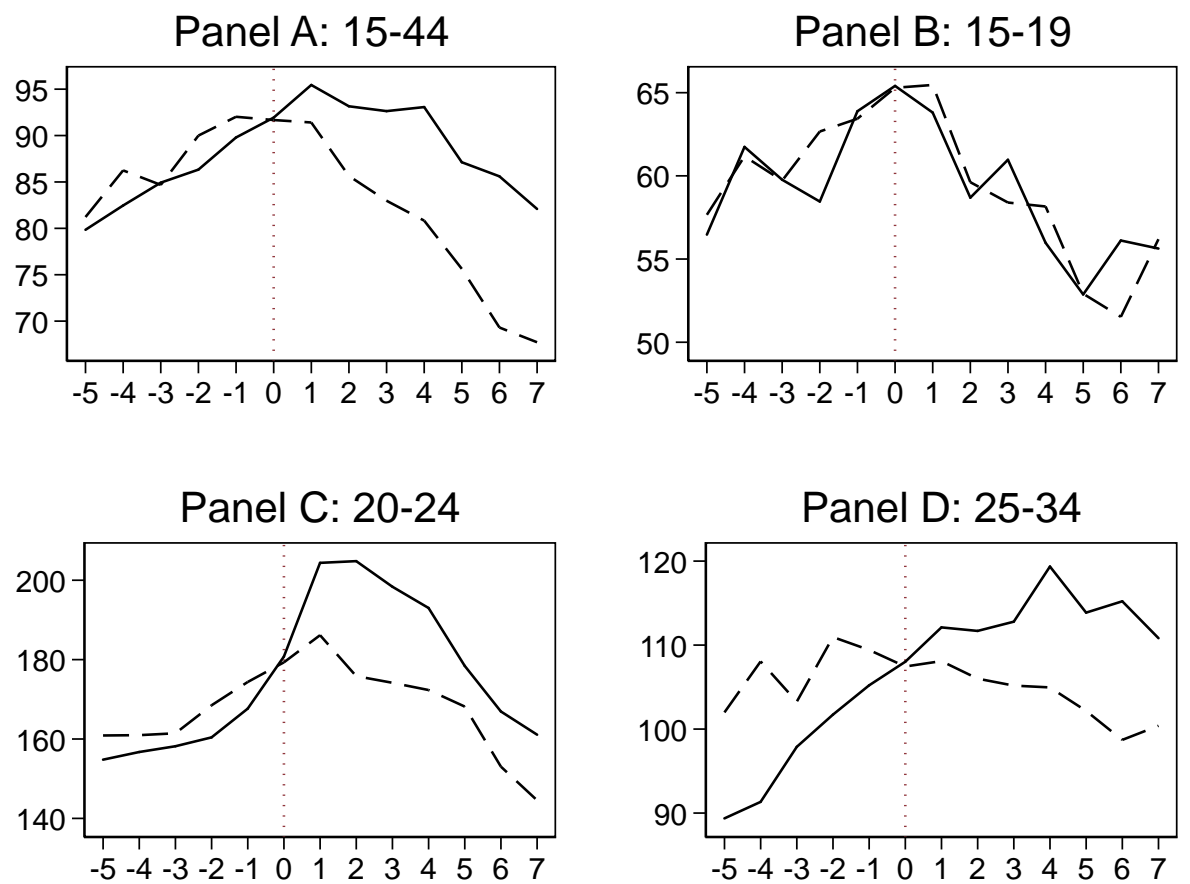

Panel E: 35-44

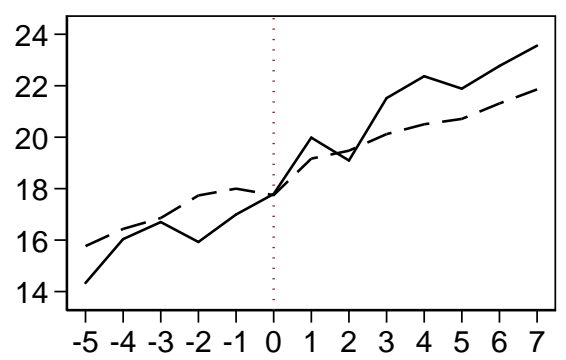

$$
\text { Alaska } \quad-- \text { SC Control }
$$

Notes: This figure shows the trends in fertility rate for Alaska and its respective synthetic controls by various age groups. The states and their corresponding weights used for the construction of the synthetic controls are reported in Table A.1. The $\mathrm{x}$-axis measures periods, in years, before and after the introduction of APFD. The year APFD was introduced, 1982, is marked by a vertical line at period zero. The $y$-axis measures number of live births per 1000 women in the respective age group. Only the last year of outcome is used in the synthetic matching process. 
Figure B.2: Comparison of Alaska and Placebo SC Effects, Fertility Rate using Last Year Method

Panel A: 15-44

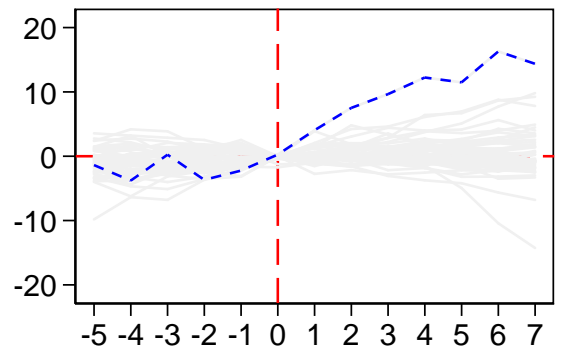

Panel C: 20-24

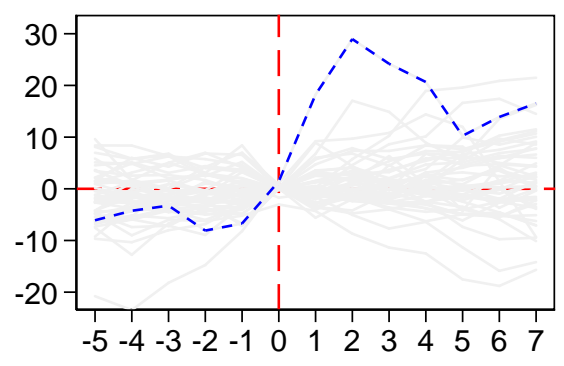

Panel E: 35-44

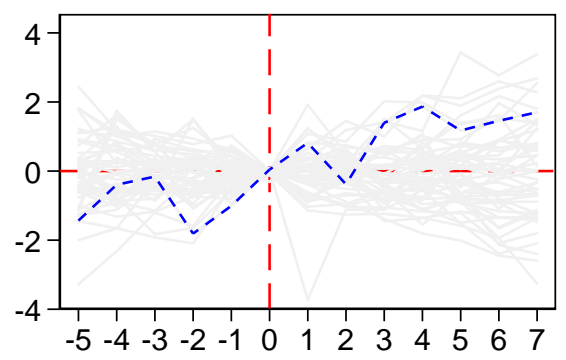

Panel B: 15-19

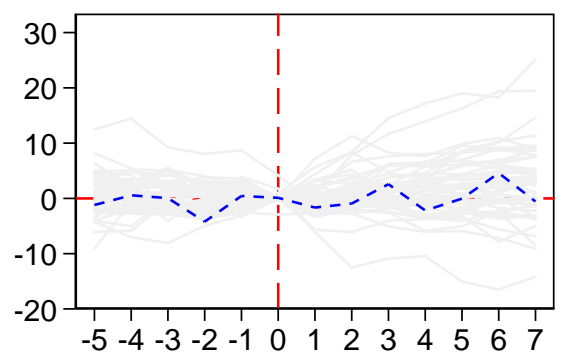

Panel D: 25-34

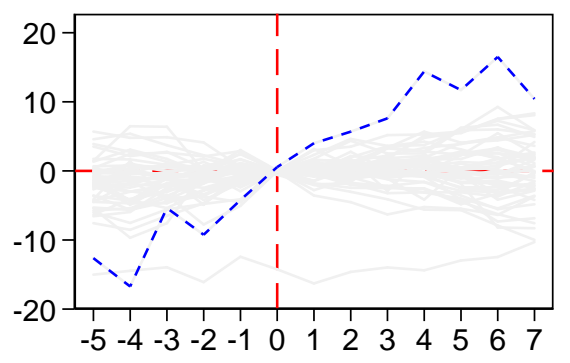

$$
\text { -- - - - Alaska Placebos }
$$

Notes: This figure shows the difference in fertility rate between Alaska and its synthetic controls (dashed series), and the differences for all placebo states with respect to its corresponding synthetic controls (gray series). The x-axis measures periods, in years, before and after the introduction of APFD. The year APFD was introduced, 1982, is marked by a vertical line at period zero. The y-axis measures the number of live births per 1000 women in the respective age group. Only the last year of outcome is used in the synthetic matching process. 
Figure B.3: Alaska and Synthetic Control Trends, Birth Spacing using Last Year Method

\section{Panel A: 15-44}

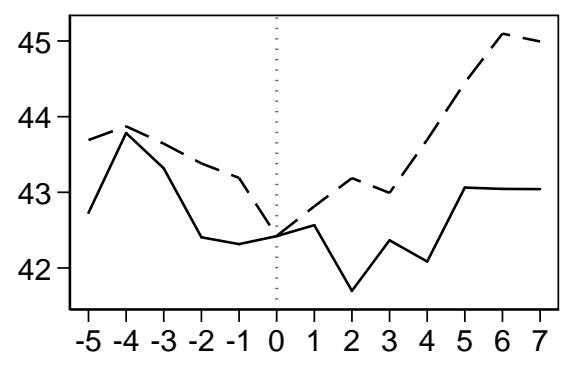

Panel C: $20-24$

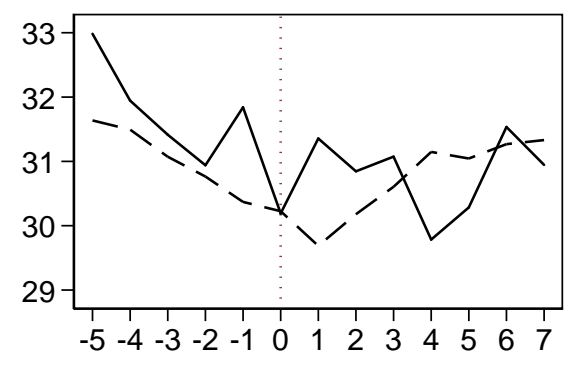

Panel E: 35-44

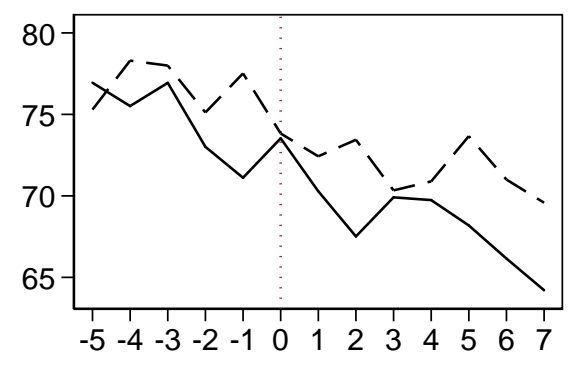

Panel B: 15-19

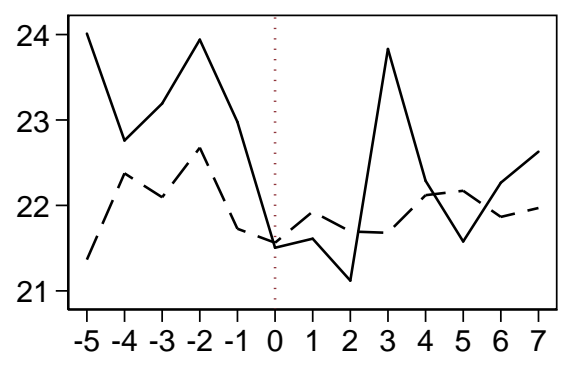

Panel D: 25-34

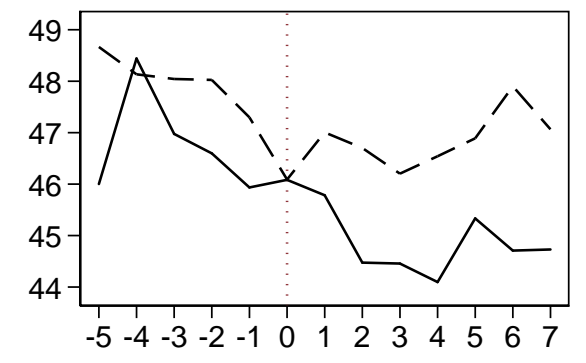

Notes: This figure shows the trends in birth spacing for Alaska and its respective synthetic controls by various age groups. The states and their corresponding weights used for the construction of the synthetic controls are reported in Table A.1. The x-axis measures periods, in years, before and after the introduction of APFD. The year APFD was introduced, 1982, is marked by a vertical line at period zero. The y-axis measures the average number of months between two live births for a woman in the respective age group. Only the last year of outcome is used in the synthetic matching process. 
Figure B.4: Comparison of Alaska and Placebo SC Effects, Birth Spacing using Last Year Method

Panel A: 15-44

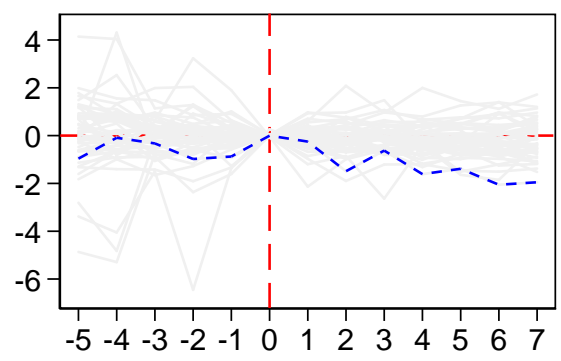

Panel C: 20-24

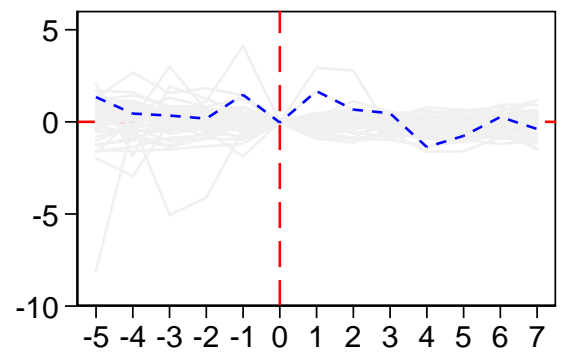

Panel E: 35-44

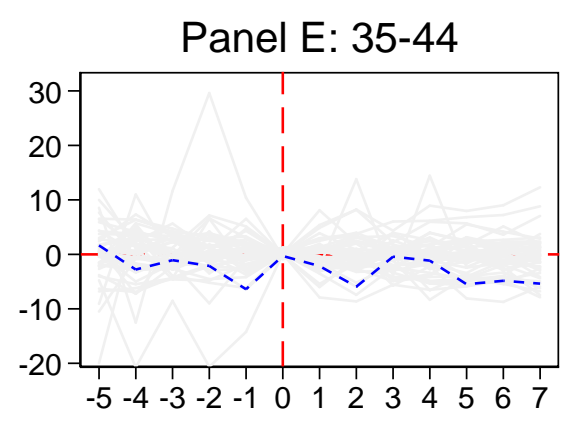

Panel B: 15-19

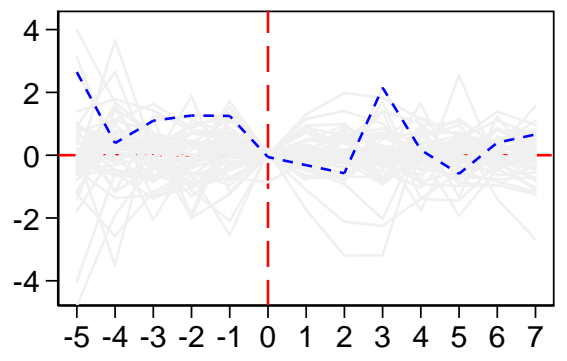

Panel D: 25-34

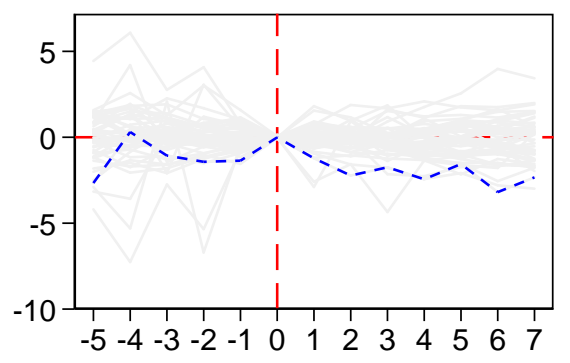

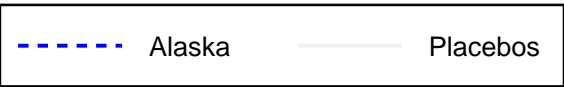

Notes: This figure shows the difference in birth spacing between Alaska and its synthetic control (dashed series), and the differences for all placebo states with respect to its corresponding synthetic controls (gray series). The $\mathrm{x}$-axis measures periods, in years, before and after the introduction of APFD. The year APFD was introduced, 1982, is marked by a vertical line at period zero. The y-axis measures the average number of months between two live births for a woman in the respective age group. Only the last year of outcome is used in the synthetic matching process. 
Figure B.5: Alaska and Synthetic Control Trend, and Comparison with Placebo SC Effects, Abortion Rate using Last Year Method
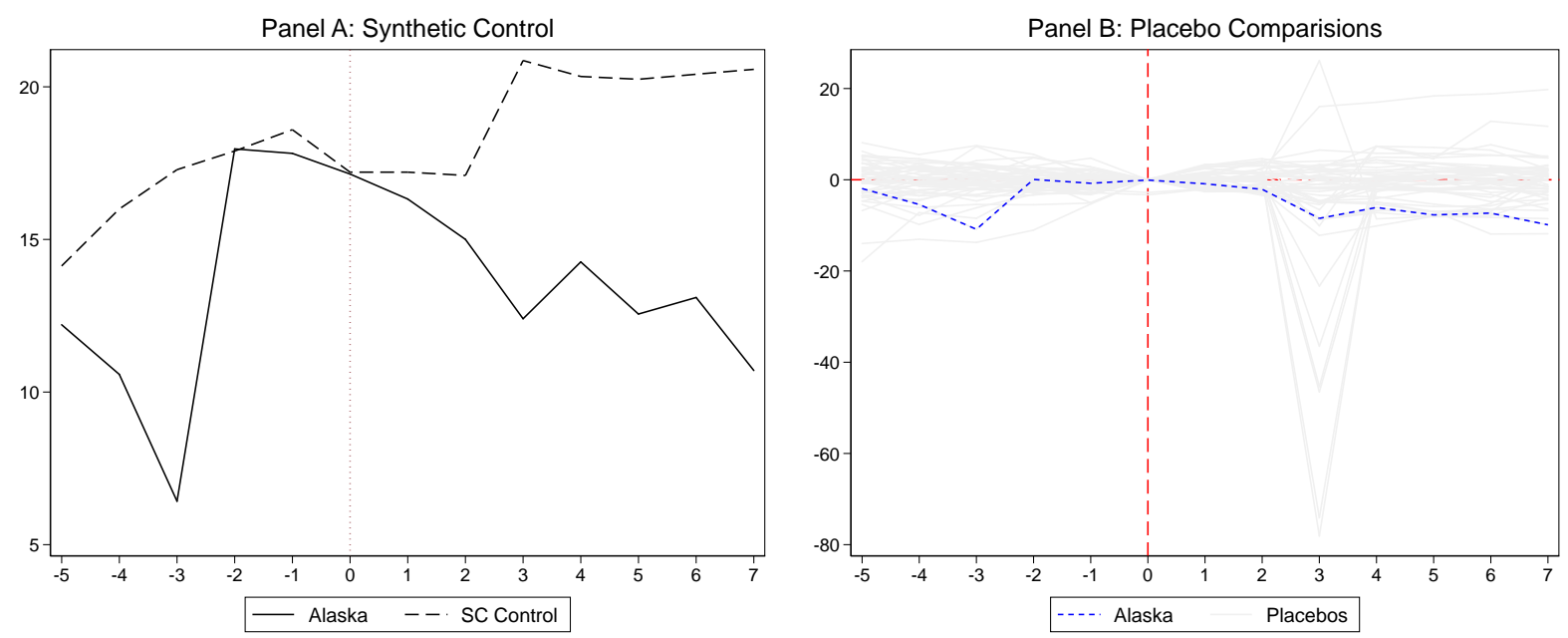

Notes: Panel A of this figure shows the trends in abortion rate for Alaska and its respective synthetic controls. Panel B shows the difference in fertility rates between Alaska and its synthetic control (dashed series), and the differences for all placebo states with respect to its corresponding synthetic controls (gray series). The states and their corresponding weights used for the construction of the synthetic control for Panel A are reported in Table A.1. The x-axis measures periods, in years, before and after the introduction of APFD. The year APFD was introduced, 1982, is marked by a vertical line at period zero. The y-axis measures the number of abortions per 1000 women in the respective age group. Only the last year of outcome is used in the synthetic matching process. 
Table B.1: Synthetic Control Weights, Last Year Method

\begin{tabular}{|c|c|c|c|c|c|}
\hline \multirow[b]{2}{*}{ State } & \multicolumn{5}{|c|}{ Panel A: Fertility Rate } \\
\hline & $15-44$ & $15-19$ & $20-24$ & $25-34$ & $35-44$ \\
\hline Connecticut & 0.000 & 0.201 & 0.000 & 0.000 & 0.000 \\
\hline $\mathrm{DC}$ & 0.045 & 0.371 & 0.000 & 0.000 & 0.459 \\
\hline Hawaii & 0.000 & 0.000 & 0.000 & 0.223 & 0.206 \\
\hline Utah & 0.000 & 0.000 & 0.000 & 0.094 & 0.116 \\
\hline \multirow[t]{3}{*}{ Wyoming } & 0.955 & 0.428 & 1.000 & 0.683 & 0.219 \\
\hline & \multicolumn{5}{|c|}{ Panel B: Birth-Spacing } \\
\hline & $15-44$ & $15-19$ & $20-24$ & $25-34$ & $35-44$ \\
\hline California & 0.000 & 0.000 & 0.000 & 0.000 & 0.335 \\
\hline Connecticut & 0.000 & 0.108 & 0.000 & 0.000 & 0.000 \\
\hline $\mathrm{DC}$ & 0.170 & 0.000 & 0.000 & 0.172 & 0.072 \\
\hline Hawaii & 0.090 & 0.469 & 0.233 & 0.076 & 0.060 \\
\hline Minnesota & 0.283 & 0.000 & 0.000 & 0.085 & 0.000 \\
\hline Utah & 0.000 & 0.000 & 0.102 & 0.000 & 0.000 \\
\hline Washington & 0.196 & 0.422 & 0.285 & 0.023 & 0.000 \\
\hline \multirow[t]{2}{*}{ Wyoming } & 0.544 & 0.000 & 0.380 & 0.644 & 0.534 \\
\hline & \multicolumn{5}{|c|}{ Panel C: Abortion Rate } \\
\hline State & $15-44$ & & & & \\
\hline California & 0.365 & & & & \\
\hline $\mathrm{DC}$ & 0.007 & & & & \\
\hline Wyoming & 0.628 & & & & \\
\hline
\end{tabular}

Notes: This table presents the weights used to construct the synthetic control for Alaska. Column (1) gives weights for synthetic Alaska for females aged 15-44. Panels (2) - (4) gives weights by age groups 15-19, 20-24, 25-34, and 35-44. Panel A provides weights for controls for study based on fertility rate, Panel B does this for birth spacing, and Panel $\mathrm{C}$ does the same for abortion rate. Only the last year of outcome is used in the synthetic matching process. Technical source: Quistorff and Galiani (2017). 
Table B.2: SC Estimates, Last Year Method

\begin{tabular}{|c|c|c|c|c|c|}
\hline & $(1)$ & $(2)$ & (3) & $(4)$ & $(5)$ \\
\hline Panel A: Fertility Rate & $15-44$ & $15-19$ & $20-24$ & $25-34$ & $35-44$ \\
\hline $\begin{array}{l}\text { Average Effect Size } \\
\text { p-value }\end{array}$ & $\begin{array}{l}10.802 \\
{[0.020]}\end{array}$ & $\begin{array}{c}0.255 \\
{[0.631]}\end{array}$ & $\begin{array}{l}18.966 \\
{[0.031]}\end{array}$ & $\begin{array}{l}10.048 \\
{[0.031]}\end{array}$ & $\begin{array}{l}1.148 \\
{[0.237]}\end{array}$ \\
\hline Number of Placebos & 357 & 357 & 357 & 357 & 357 \\
\hline Pre-Preriod RMSPE & 2.410 & 1.811 & 5.452 & 9.766 & 1.038 \\
\hline RMSPE Percentile & 0.769 & 0.492 & 0.816 & 0.943 & 0.792 \\
\hline Panel B: Birth Spacing & $15-44$ & $15-19$ & $20-24$ & $25-34$ & $35-44$ \\
\hline $\begin{array}{l}\text { Average Effect Size } \\
\text { p-value }\end{array}$ & $\begin{array}{l}-1.338 \\
{[0.174]}\end{array}$ & $\begin{array}{c}0.271 \\
{[0.374]}\end{array}$ & $\begin{array}{c}0.080 \\
{[0.254]}\end{array}$ & $\begin{array}{l}-2.104 \\
{[0.089]}\end{array}$ & $\begin{array}{l}-3.621 \\
{[0.360]}\end{array}$ \\
\hline Number of Placebos & 357 & 357 & 357 & 357 & 357 \\
\hline Pre-Preriod RMSPE & 0.678 & 1.368 & 0.848 & 1.425 & 3.040 \\
\hline RMSPE Percentile & 0.581 & 0.911 & 0.772 & 0.821 & 0.576 \\
\hline Panel C: Abortion Rate & $15-44$ & & & & \\
\hline $\begin{array}{l}\text { Average Effect Size } \\
\text { p-value }\end{array}$ & $\begin{array}{c}-6.054 \\
{[0.243]}\end{array}$ & & & & \\
\hline Number of Placebos & 357 & & & & \\
\hline Pre-Preriod RMSPE & 4.993 & & & & \\
\hline RMSPE Percentile & 0.806 & & & & \\
\hline
\end{tabular}

Notes: This table presents estimates of SC studies. The estimates are averaged over the post-treatment period: $\hat{\theta}_{1}=$ $\sum_{t=T_{0}+1}^{T} \frac{1}{\left(T-\left(T_{0}+1\right)\right)} \hat{\theta}_{1, t} \cdot p$-value is calculated using the permutation test described in equation 13. Root Mean Square Prediction Error (RMSPE) is calculated for Alaska for the years 1976-1982. RMSPE percentile is based on the RMSPE for each of the 50 placebo studies. Only the last year of outcome is used in the synthetic matching process. 